\title{
Material Allowable Generation and AM Process Parameters Effect on Porosity
}

\author{
Frank Abdi ${ }^{1, *}$, Parviz Yavari ${ }^{2}$, Vasyl Harik ${ }^{1}$ and Cody Godines ${ }^{1}$ \\ 1 Alpha STAR Corp., 5150 East Pacific Coast Highway, Suite 650, Long Beach, CA 90804, USA; \\ vasyl.harik@alphastarcorp.com (V.H.); cody.godines@alphastarcorp.com (C.G.) \\ 2 Aerospace System Northrop Grumman Corporation, El Segundo, CA 90245, USA; parviz.yavari@ngc.com \\ * Correspondence: fabdi@alphastarcorp.com; Tel.: +1-562-961-7827
}

Received: 20 May 2020; Accepted: 16 June 2020; Published: 30 June 2020

check for updates

\begin{abstract}
Additive manufacturing (AM) process methods such as powder bed fusion (LPBF) of metal powder layers can produce layered material systems with designed microstructures, which may exhibit scatter in mechanical properties (e.g., lower yield and lower failure strain), corrosion due to porosity and print anomalies. This study shows the development of AM process simulation to predict As-built material characteristic and their scatter comparing with experimental test data. ICME (Integrated Computational Materials Engineering) was used to simulate yield, ultimate, strain, and reduction of the area of sample AM. The method was extended to predict oxidation and damage of as-built parts. The samples were fabricated horizontally and vertically in multiple and scatter directions to find the effect on the mechanical properties such as ultimate tensile strength (UTS) and yield strength (YS). The probabilistic sensitivities show that in order for the next-generation technology to improve the strength of 3D printed materials, they must control the void volume fraction (trapped gas) and orientation of voids. The studied 3D print modality processes: (a) LPBF of AlSi10Mg, and (b) Electron Beam (EBM) of Ti-6Al-4V materials are shown to be over 99.99\% reliable. The statistics of 3D printed Ti-6Al-4V have been observed for room and high temperature (RT/HT). The ICME Material Characterization and Qualification (MCQ) software material model prediction capabilities were used to predict (a) Material Allowable, a variation in Stress Strain Curves Characteristic Points and Residual Stress due to air particle (void/defect) shape and size and orientation. The probabilistic simulation computes Cumulative Distribution Function (CDF) and probabilistic sensitivities for YS, UTS, and \%Elongation as well as A and B basis allowable of the As-Built 3D printed material and; and (b) Fracture Control Plan fracture toughness determination, and fatigue crack growth vs. stress intensity.
\end{abstract}

Keywords: additive manufacturing (AM); allowable generation; AS-built mechanical property generation; fracture control plan; scatter in build direction; porosity; ASTM standard; AM modality process (LPBF; DMLS; EBM)

\section{Introduction}

\subsection{Problem}

According to ASTM F2792, there are currently seven recognized families of AM. Those families are: (1) Sheet Lamination; (2) Material Extrusion; (3) Direct Energy Deposition (DED); (4) VAT Photopolymerization; (5) Powder Bed Fusion; (6) Binder Jetting and (7) Material Jetting. Each modality has its own quirks and shortcomings when attempting to fabricate qualified parts while avoiding build anomalies. Identifying the correct process parameters to achieve this goal generally involves trial and error. Further, print strategy can vary from machine to machine. As such, manufacturing 
defects are a common concern of all AM platforms and all AM processes, including metal, polymer, and ceramic. The proposed technology will include prediction of temperature-dependent material properties by implementation of nano-mechanics-based inclusion theory considering the effect of defects, environment, geometry, and pathing errors. This effort is applicable to all families of AM but will focus on Metal AM. Particular emphasis will be placed on Powder Bed Fusion that considers Selective Laser Melting (SLM) and Electron Beam Melting (EBM), which both exhibit anomalies and residual stress (RS) during and after the build. Here, qualification is an afterthought due to the presence of net shaping, cracks, surface roughness, scatter in mechanical properties, and lower plasticity/strain in comparison with traditional manufacturing.

AM parts may exhibit printing local defects such as balling, keyhole pores (high power, low speed), humping (Meltpool Pile-up), unfused powder (high velocity, low power), and delamination (Figure 1), which are related to thermal processes, i.e., Heating, Melting, Melt-Superheated, Superheat-Cooling, Solidification, and Cooling. The resulting micro defects, which take the form of intergranular cracks, surface cracks "dendrite", surface roughness, micro/macro voids, distortion, warpage, wrinkles, shrinkage, and residual stress have a profound effect on part qualification and performance. In the case of surface roughness, post heat treatment and/or surface removal may be used as a remedy, but such a solution may cause additional grain growth, loss of material plasticity, more intergranular cracks, and sometimes, collapse of the specimen. Fortunately, advanced Integrated Computational engineering (ICME) tools are available to utilize material data, machine data and thermal history to identify optimal build solutions that minimize and/or eliminate manufacturing anomalies. However, these solutions tend to be machine-specific and require the duplication of the ICME methodology on each and every platform for each and every part.
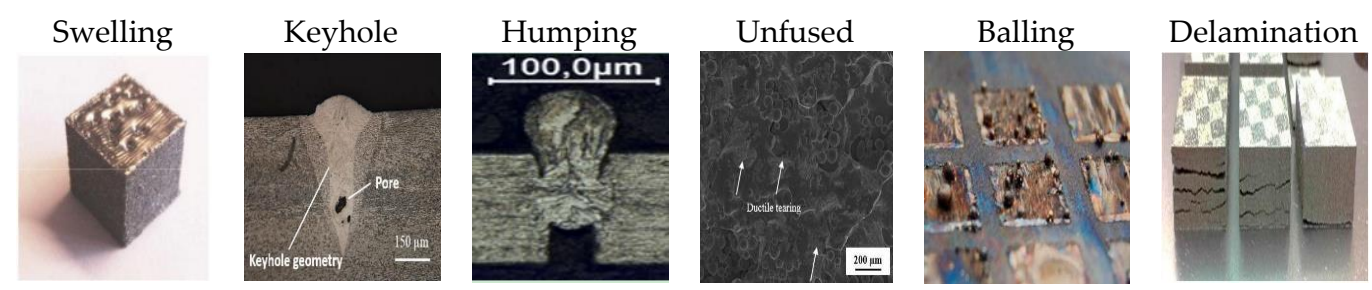

Figure 1. AM local defects-courtesy (https://www.insidemetaladditivemanufacturing.com).

\subsection{AM Part Qualification}

AM LPBF material exhibits scatter and uncertainty due to various build anomalies (Table 1) and variation in machine parameters (Table 2). It should be noted that the referenced anomalies correspond to manufacturing errors that must be measured, controlled and mitigated in order to achieve part qualification as dictated by NIST, DOD, and ASTM [1-3]. Since each process parameter may impact the results of a build, it is critical to assess the sensitivity of each parameter in relation to the referenced anomalies.

Table 1. AM Part Qualification Steps and Criteria.

\begin{tabular}{ll}
\hline \multicolumn{1}{c}{ Qualification Category } & \multicolumn{1}{c}{ Description } \\
\hline 1-Micro defects & $\begin{array}{l}\text { Micro voids/Density during thermal history, super melting sintering and } \\
\text { solidification }\end{array}$ \\
\hline 2-Macro defects & Macro porosity: Printing error around hole and boundary \\
\hline 3-Surface roughness & Diffusional creep, Triaxial stress \\
\hline 4-Intergranular cracks & Diffusional creep, Biaxial stress \\
\hline 5-Scatter in material properties & $\begin{array}{l}\text { Stress-strain relation (yield stress, ultimate/plastic strain) due to voids (micro/macro) } \\
\text { and cracks }\end{array}$ \\
\hline 6-Fracture control plan & Characterization of fracture properties, fatigue crack growth, stress intensity curve \\
\hline
\end{tabular}


Table 1. Cont.

\begin{tabular}{ll}
\hline \multicolumn{1}{c}{ Qualification Category } & \multicolumn{1}{c}{ Description } \\
\hline 7-Warpage & Evaluation of support, Residual stress \\
\hline 8-Net shape & Residual stress, Baseplate removal \\
\hline 9-As-built performance & In-service loading \\
\hline 10-Post heat treatment & Grain growth, lower strain; thermal analysis \\
\hline
\end{tabular}

Table 2. AM machines primary process parameters.

\begin{tabular}{|c|c|c|c|}
\hline Item & Parameter & Description & $\begin{array}{l}\text { Controlled or } \\
\text { Predefined }\end{array}$ \\
\hline 1 & Average Power, $P$ & Total Energy Output of Laser & Controlled \\
\hline 2 & Scan Velocity, $v$ & Velocity of laser across surface & Controlled \\
\hline 3 & Scan Spacing, $S_{\mathrm{s}}$ & Distance between neighboring passes & Controlled \\
\hline 4 & Scan Strategy & Pattern of laser scanning (spirals, zig-zag) & Controlled \\
\hline 5 & $\begin{array}{c}\text { Deposition System } \\
\text { Parameters }\end{array}$ & Recoater velocity, pressure, type, dosing & Controlled \\
\hline 6 & Layer Thickness, $L$ & Height of single powder & Controlled \\
\hline 7 & Powder bed temperature, $T_{\mathfrak{p}}$ & Build temperature of powder bed & Controlled \\
\hline 8 & Oxygen Level, $\% \mathrm{O}_{2}$ & Likely most important environment parameter & Controlled \\
\hline 9 & Gas Flow Velocity, $v_{\mathrm{g}}$ & Influences convective cooling & Controlled \\
\hline 10 & Ambient Temperature, $T_{\mathrm{inf}}$ & Affecting cooling, rehear and residual stress & Controlled \\
\hline
\end{tabular}

For example, variation in one parameter, such as hatch spacing, can result in dramatic changes to stable and unstable print zones in an AM LPBF process. The key steps in the qualification of AM parts are: (1) optimization of process parameters; (2) porosity minimization; (3) surface roughness minimization; (4) tolerance minimization and net shape assessment due to residual stresses, baseplate removal, and residual deflection; (5) prediction of mechanical properties and stress-strain curve, as well as scatter and uncertainty of yield and ultimate stress/and strain; (6) establishment of fracture control plan and accepted threshold crack size; (7) effect of post heat treatment on part quality; and (8) part performance under service loading. Primary (Controllable) Process Parameters, shown in Table 2, are a subset of all 55 parameters [4] non controllable (not allowed by machine) and approximately 10 controllable parameters. The table applies to: (1) Laser Powder Bed Fusion (LPBF) including: Selective Laser Sintering (SLS), Selective Laser Melting (SLM), and Electron Beam Melting (EBM); (2) Powder Directed Energy Deposition including: Laser Engineering Net Shape (LENS), and Laser Metal Deposition-powder (LMD-p); and (3) Wire Directed Energy Deposition including: Laser Metal Deposition-wire (LMD-w), and Electron Beam Additive Manufacturing (EBAM@). Data necessary to support part qualification may be taken from either: (1) in situ AM machine sensory data (i.e., photo diode, thermal camera, profilometer, meltpool, surface roughness, temperature heat flux) and/or; (2) ICME-generated tool sets such as: (a) thermal management tools for prediction of: (i) melt pool, (ii) process map, and (iii) micro void generation; and (b) material modeling, characterization, and qualification tools for predicting the stress-strain curve, residual stress/strain, and mechanical property such as strength, allowables, uncertainty/sensitivity generation and fracture property control prediction.

\subsection{Machine Process and Modality (LPBF, EBM)}

Powder Bed Fusion (PBF) is one of the seven categories of AM processes defined in ASTM F2792 [5]. PBF processes use thermal energy to selectively fuse areas of a layer of powder using laser or an electron beam as the energy source [6]. When the energy source traces the geometry of an individual layer onto the top surface of the powder bed, the energy from the beam spot is absorbed by the exposed powder, causing that powder to melt. This small molten area is often described as the melt-pool. Individual powder particles are fused together when the melt-pool re-solidifies. After one layer is completed, the build platform is lowered by the prescribed layer thickness, and a new layer of 
powder from the dispenser platform is swept over the build platform, filling the resulting gap and allowing a new layer to be built.

Some varieties/variations of Powder Bed Fusion (PBF) processes use low-power lasers to bind powder particles by only melting the surface of the powder particles (called selective laser sintering or SLS) or a binder coating the powder particles. These processes produce green parts that require further post-processing to infiltrate and sinter the parts to make them fully dense. Another class of PBF processes uses high-power energy beams to fully melt the powder particles, which then fuse together to the previous layer(s) when the molten material cools, e.g., selective laser melting (SLM), direct metal laser sintering (DMLS), or electron-beam melting (EBM). Repeating this process, layer-by-layer, directly results in a part with near $100 \%$ density, even in metals. These processes are of primary interest to this study.

The electron Beam Melting (EBM) machine process includes: (1) CAD File Sliced into thin layers, (2) coils used for focus and scanning and (3) electrons accelerated onto a powder bed. Advantages include: (a) No tooling required—unlike castings; (b) performed in vacuum environment-produces clean material; (c) performed in a hot powder bed-allows for complex shapes, stress relief as part of process, and no residual stresses; (d) melting takes places in seconds-extremely fine grain size; (e) process is rapid-10 lb part fabricated within $24 \mathrm{~h}$; and (f) powder utilization is nearly $>90 \%$.

Disadvantages include: (1) produces a coarse surface finish; (2) design must allow for powder removal; (3) maximum size of machine build volume: $8^{\prime \prime} \times 8^{\prime \prime} \times 14^{\prime \prime}$; and (4) exhibits oxidation on some powder materials. Figure 2 shows the Electron Beam Melted vs. Wrought for Ti-6Al-4V Microstructure Comparison. As shown, the material Characteristics are: (i) Uniform, Fine Grain; (ii) Columnar; (iii) Lamellar Alpha Phase; and (iv) Larger Beta Grain. The source of unconsolidated powder as shown in Figure 2 is not understood. This type of flaw is similar to a leaner defect and will drastically impacts the fatigue life of the EBM parts.

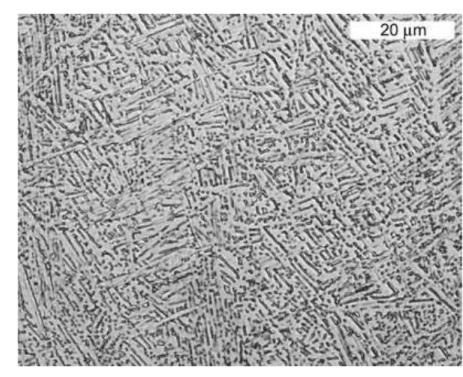

(a)

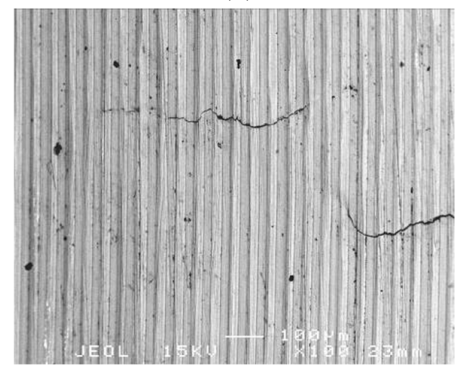

(c)

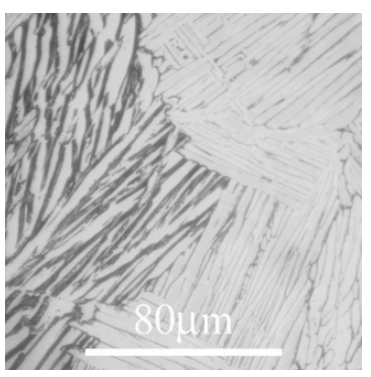

(b)

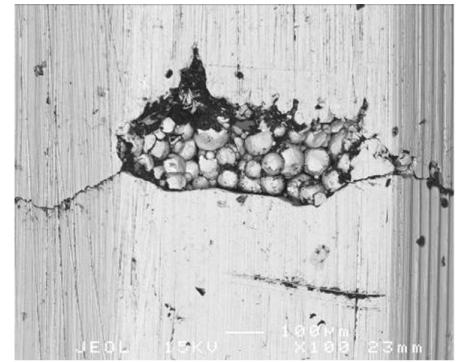

(d)

Figure 2. Electron beam melted vs. wrought, Ti-6Al-4V microstructure comparison: (a) EBM, Mag: $1270 \times$ (Calculated); (b) wrought, Mag: 570× (Calculated); (c) electron micrographs of Crack A showing the extent of the Crack Tip (c) and the powder consolidation flaw (d) on the inner surface.

The microstructure produced using electron beam powder bed (EBPB) and laser beam powder bed (LBPB) techniques as well as wire fed laser beam (WFLB) is a typical alpha/beta microstructure of Ti-6Al-4V. The morphology of the porosity for EBPB and LBPB differed significantly [7]. The LBPB-processed material exhibited irregular-shaped pores, whereas the EBPB produced spherical 
pores. It may be further noted that the DMLS systems produced surfaces approximately twice as smooth as the EBM. The surface condition is most important for fatigue critical parts intended for use in their "as-fabricated" net shape condition. This is especially relevant for parts with complex internal features where surface finishing of entire part may be impracticable.

In summary, when properly processed, the static mechanical properties of AM metallic materials are comparable to conventionally fabricated metallic components. The relatively high cooling rates achieved reduce partitioning and favor reduced grain sizes. However, AM-fabricated materials do exhibit microstructural and mechanical property anisotropy with the Z-direction generally being the weakest. Dynamic properties of AM produced alloys are dominated by defect structures, viz., micro-porosity and surface finish. However, properly processed HIPed and finished machined AM alloys can exhibit fatigue properties on parity with those of wrought alloys.

\subsection{Allowable Generation}

The direct computation methods of the MMPDS [2] are appropriate to determine the T99 values for this design value assessment for ultimate tensile strength (UTS). Evaluation of the Pearson (three-parameter gamma) and Weibull distributions using the appropriate modified Anderson-Darling tests show that either distribution is acceptable. The Pearson model gives a T99 for the UTS of 191.0 for 17-4 PH stainless steel, which is seen as a high value [2]. The data and fit are illustrated in Figure 3. Tensile testing for UTS, yield strength (YS), and elongation according to ASTM E8/E8M, Standard Test Methods for Tension Testing of Metallic Materials, is required for all builds. For consistency in evaluation, tensile witness specimen geometry and build orientation are standardized to remain consistent with those specimens used to establish the acceptance criteria. Tensile witness specimens are expected to represent the full Z-height of the build and, to the degree possible, be positioned behind the part relative to the travel direction of the powder re-coater. Tensile specimens are commonly stacked atop each other to cover the Z-height of the build. Depending on the part height and tensile specimen design, more than one stack is generally needed. The best policy is to allow for alternating tensile specimen gage locations in the stacks to provide the best possible test coverage of the Z-height [3].

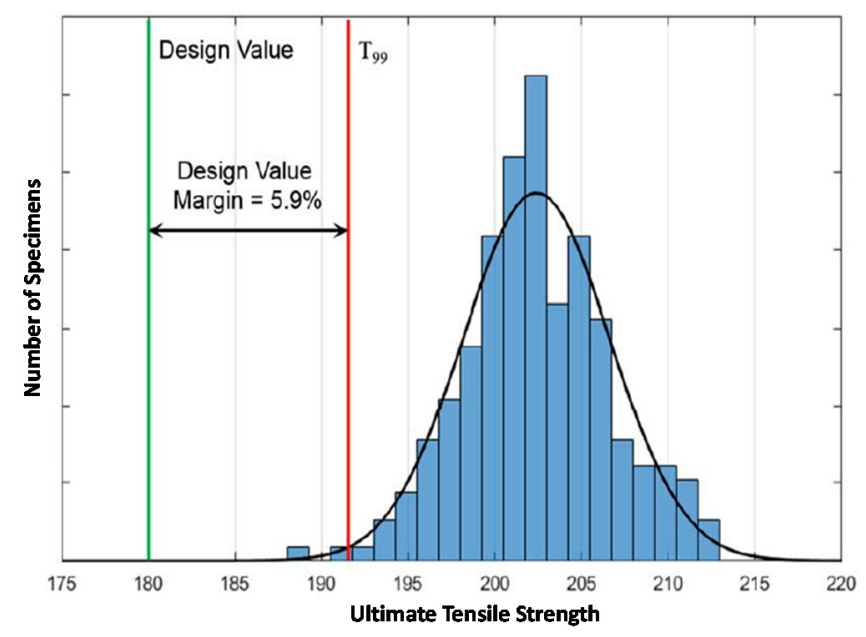

Figure 3. Substantiation of design value from MPS data.

Print orientation effect on tensile strength and strain has an effect on Tensile properties of the vertically and horizontally oriented SLM 17-4 PH SS specimens, in either their as-built (AB) or heat treated (HT) condition [8] are presented in Figure 4. The results indicate that building orientation during SLM and post-manufacturing heat treatment (solution annealing plus peak-aging) have significant effects on the monotonic tensile behavior of SLM 17-4 PH SS. Yield and ultimate tensile strengths were significantly affected by the post-manufacturing heat treatment, while elongation to failure was mostly influenced by part building orientation. The effects of heat treatment on the investigated SLM 
parts are attributed to the formation of precipitates in the material matrix, as well as the altering of other microstructural features, i.e., phase volume fraction, grain size and morphology, while the build orientation has direct influence on the damage evolution under loading. A part's building orientation during SLM influences its cooling rate (due to the part's aspect ratio), and thus encumbered microstructure, while the final orientation of deposited layers (which depend on build direction) impacts part strength in various loading directions. For instance, the vertically oriented SLM samples consist of deposited layers perpendicular to the investigated loading direction and this can impact its tensile strength [8].

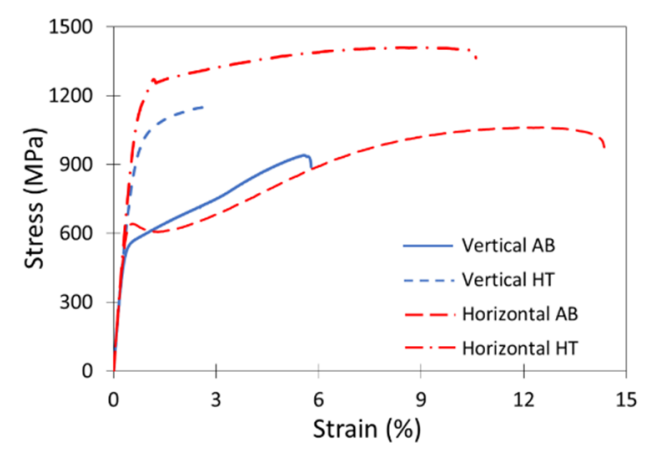

Figure 4. Engineering stress-strain curves of SLM 17-4 PH SS in different conditions.

\section{Methodology}

The defined approach is based on ICME-driven Thermal Modeling and Material CharacterizationQualification (MCQ) including Fracture toughness determination, and fatigue crack growth Model. In the following paragraphs, each critical module will be explained in detail.

\subsection{ICME Simulation Elements}

The individual components of ICME simulation consist of Multi-Scale Modeling of Thermal, Mechanical, Material properties, Process Modeling, and Part Qualification with/without In-Situ Monitoring [9]. They in turn support: (1) A thermal management approach to rapidly calculate thermal profile, material state and process map, (2) a global local FEM approach to calculate cracks, oxidation, surface roughness using diffusional creep approach, (3) a fracture mechanics approach to determine fracture properties for a 3D printed material system and (4) a DOE (design of Experiment ) Surrogate Meta modeling approach is used to optimize print parameters to minimize surface roughness and obtain a better surface finish. ASC's current ICME-based 3D printing capability will be used as baseline for the proposed metal AM process simulation. The current 3D printing computational tools include material characterization, machine G-code data processing, mesh generation from G-code, STL file smoothing, as well as assessment of distortion, residual stress, deflection and damage and fracture evolution using a coupled thermo-mechanical solution for both metal and polymer-reinforced plastics. Figure 5 depicts the current process flow strategy including material modeling and part qualification. Material Characterization and Qualification (MCQ) software capability accounts for inclusion (particulate) to formulate the stress-strain curve in both the longitudinal and transverse direction. Micromechanics and fracture mechanics approaches have been developed (Figure 5a) for the evaluation of the overall properties of heterogeneous materials and their dependence on the properties of constituents and the microstructure of materials. They are mainly based on Eshelby's equivalent inclusion theory [10]. A nano-micromechanics-based theory proposed by Mori-Tanaka and Eshelby is used to demonstrate the capability of MCQ software to predict stress-strain curves with effect of inclusions. 


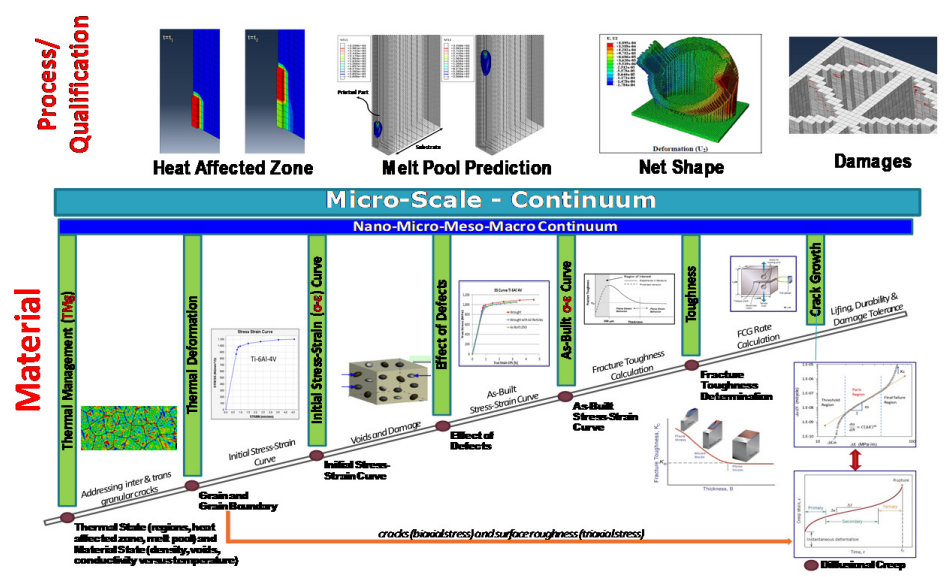

(a)

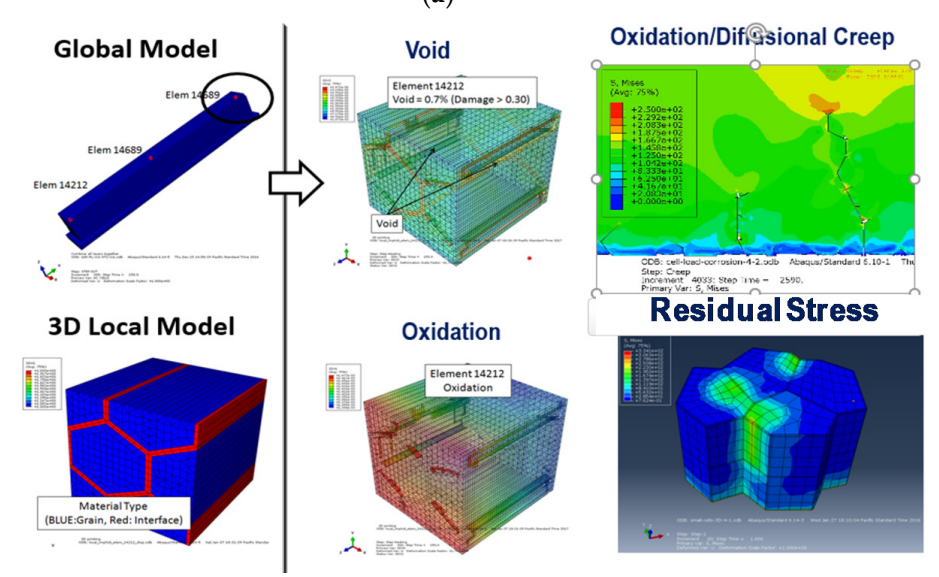

(b)

Figure 5. Integrated Computational Materials Engineering (ICME) Model Generator; Material modeling; process modeling, in-service Qualification: (a) Material (mechanical, fracture, fatigue), and Part Qualification; (b) Process, and Grain Modeling.

For Fracture Toughness Determination (FTD), the extended the Griffith theory is used to estimate the fracture toughness value of metallic alloys from simple uniaxial tensile tests. For Fatigue Crack Growth (FCG), the Fatigue Crack Growth rate curve (or da/dN vs. $\Delta \mathrm{K}$ ) can be generated by applying the fracture toughness value, $K_{\mathrm{C}}$ (obtained from the extended Griffith theory) for the accelerated region, Paris region, and threshold regions [11].

Part qualification uses Durability and Damage Tolerance (D and DT) to assess the integrity of complex structures by performing a Multi-Scale Progressive Failure Analysis and investigating what type of damage initiates; how it propagates and how it leads to failure of the structure. Process Modeling (Figure 5b) capability for powder metal includes the prediction of 3D printed global structure finite element model (FEM) net shape, residual stress, and local Grain Modeling, diffusional creep using Voronoi tessellation Mesh (2D and effect of inclusion predicts intergranular, and trans-granular cracks, residual stress and strain, and surface roughness, or 3D FE Mesh, predicting surface roughness creep diffusion and intergranular and transgranular cracks, which will lead to rupture) High values of triaxial tension can trigger void nucleation and growth leading to reduced creep ductility and creep-brittle behavior. Using the elastic/plastic/creep modeling in the FEA allows the model to predict creep cracking based upon the multiaxial failure strain levels. Additive manufacturing process simulation developed by ASC includes both thermal and structural changes and is represented by coupled thermal-structural finite element (FE) analysis. A transient coupled thermo-mechanical model is used to simulate the manufacturing behavior when the fabricated part becomes distorted and stress is built up during manufacturing because of the repeated heating and cooling. In-situ monitoring is used to measure surface roughness with big data processing. 


\subsubsection{Surface Roughness-Creep Intergranular Damage and Multisite Crack Evolution Model}

At high temperatures, metals exhibit creep, which will lead to rupture. High values of triaxial tension can be calculated on a detail grain and grain boundary model that can trigger void nucleation and growth leading to reduced creep ductility, creep-brittle behavior, and surface roughness. Using the elastic/plastic/creep modeling in the FEA allows the model to predict creep cracking based upon the multiaxial failure strain levels. At high temperatures, metals exhibit rate-dependent (creep) deformation under constant load. Unless another failure mechanism intervenes, creep deformation will eventually lead to rupture, which is generally associated with the coalescence of voids along grain boundaries. An expression for multiaxial creep ductility is based on a mechanism of grain boundary cavitation for a power law creep material [12,13]

$$
\frac{\varepsilon_{\mathrm{f}}^{*}}{\varepsilon_{\mathrm{f}}}=\sinh \left[\frac{2}{3}\left(\frac{\mathrm{n}-1 / 2}{\mathrm{n}+1 / 2}\right)\right] / \sinh \left[2\left(\frac{\mathrm{n}-1 / 2}{\mathrm{n}+1 / 2}\right) \frac{\sigma_{\mathrm{m}}}{\sigma_{\mathrm{c}}}\right]
$$

Here, $\varepsilon_{f}$, is the failure strain for uniaxial stress; $n$, is a slope, or more specifically, a material constant equivalent to one over strain rate sensitivity. The other parameters are: $\sigma_{\mathrm{m}}$-the ratio between the mean (hydrostatic) stress, and $\sigma_{\mathrm{c}}$ is the equivalent (von Mises) stress.

\subsubsection{Fracture Toughness and Fatigue Crack Growth Model}

The information from a complete stress-strain curve is used to estimate the fracture toughness based on the energy method [11]. The Fracture Toughness Determination code (FTD) is a useful tool that can generate the plane strain and plane stress fracture toughness for metallic alloys by using the material static properties. In addition, it can provide material fracture toughness as a function of part thickness. In Part II, the plane strain and plane stress fracture toughness (KIC and KC) were used to generate the fatigue crack growth rate data (da/dN vs. $\Delta \mathrm{K}$ curve). The Fatigue Crack Growth (FCG) is established to generate the whole region of the da/dN versus $\Delta K$ curve [11]. da/dN versus $\Delta K$ curve is used to predict the fatigue life and residual strength in conjunction with finite element analysis (FEA). Material residual strength capability curve (a plot of fracture stress versus half a crack length) can be generated through the extended Griffith theory $[5,6]$. Energy absorption rate for plastic deformation at the crack tip is calculated and used to establish a relationship between fracture stress and half critical crack length. The total energy per unit thickness absorbed in plastic straining of the material around the crack tip, $U_{P}$, can be written as follows:

$$
U_{\mathrm{P}}=U_{\mathrm{F}}+U_{\mathrm{U}}
$$

where $U_{\mathrm{F}}$ and $U_{\mathrm{U}}$ are the energy absorbed per unit thickness in plastic straining of the material beyond the ultimate at the crack tip and below the ultimate stress near the crack tip, respectively. The extended energy balance equation, in terms of $U_{F}$ and $U_{U}$, described by Equation (1), can be rewritten as follows:

$$
\partial\left[U_{\mathrm{E}}-U_{\mathrm{S}}-U_{\mathrm{F}}-U_{\mathrm{U}}\right] / \partial \mathrm{c}=0
$$

where $U_{\mathrm{E}}$ and $U_{\mathrm{S}}$ are the total available energy and energy necessary to create two new crack surfaces. $g_{1}=\partial U_{\mathrm{F}} / \partial \mathrm{c}$ and $g_{2}=\partial U_{\mathrm{U}} / \partial \mathrm{c}$ are the rates at which energy is absorbed in plastic straining beyond the ultimate stress at the crack tip and below the ultimate stress near the crack tip, respectively. The extended Griffith theory in terms of $g_{1}$ and $g_{2}$ can be rewritten as follows:

$$
\frac{\pi \sigma^{2} \mathrm{c}}{\mathrm{E}}=2 \mathrm{~T}+\frac{\partial \mathrm{U}_{\mathrm{F}}}{\partial \mathrm{c}}+\frac{\partial \mathrm{U}_{\mathrm{U}}}{\partial \mathrm{c}}
$$

where $\partial U_{\mathrm{S}} / \partial c=2 T$, the work done in creating two new crack surfaces. 


\subsubsection{Thermal Management-Micro-Thermal Management (TMg)}

TMg Predicts: (i) Process Map, (ii) Thermal State (heating, melting, superheated-melt, superheated-cooling, consolidation/sintering, cooling) (Figure 6), (iii) Material State (Void, density, VOS), and (iv) Phase diagram, crystallization and composition contribution. Finite difference Zeroth-Order Model algorithm was developed towards modeling of real-time calculation/prediction of Thermal History in laser powder bed fusion (LPBF) process for both laser scanning (power and speed) and laser stationary (power) analyses [14]. TMg has been validated for Titanium [15] with respect to dynamic evolution of melt pool depth-width. TMg predicts Material State and can be used to define a dynamic Process Map that relates common manufacturing anomalies to laser power and speed. Software has been previously validated for INC-718, Ti64, SS-316L, and AlSi10Mg. TMg was also validated for Stainless Steel for an LPBF platform. Here, the dynamic process map (P-V-T envelope) and the zones of stabilities and instabilities were validated for a single track of laser moving at different laser power and scan speed (range of P: $150-700 \mathrm{~W}$ and V: $300-750 \mathrm{~mm} / \mathrm{s}$ ). The predicted zones such as balling, humping, and stable regions) were compared with the literature data [16] and were in good agreement (Figure 7).

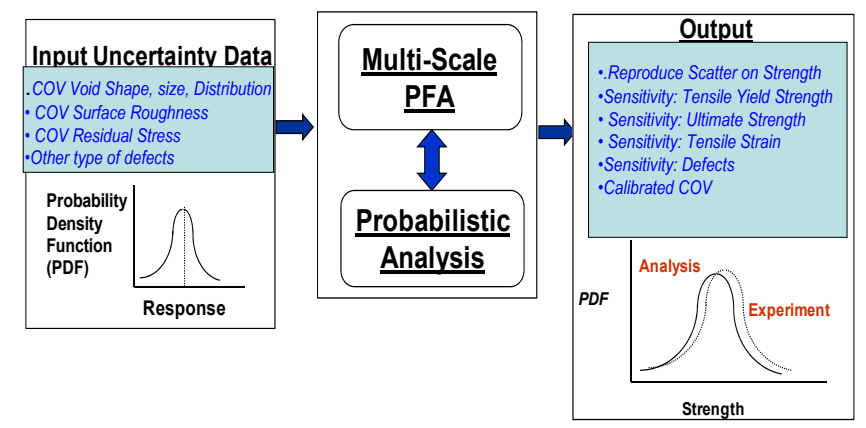

Figure 6. Process for Reproducing Scatter from Testing.

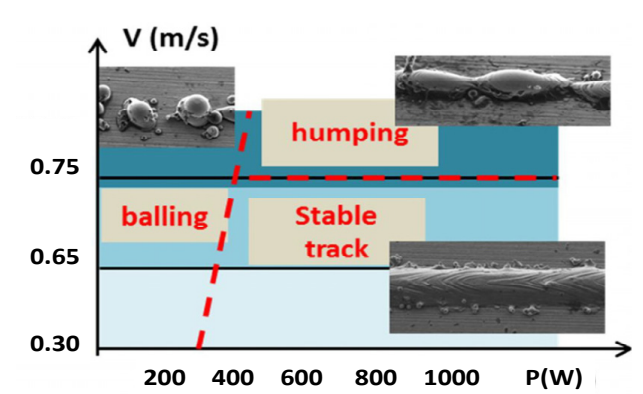

(a)

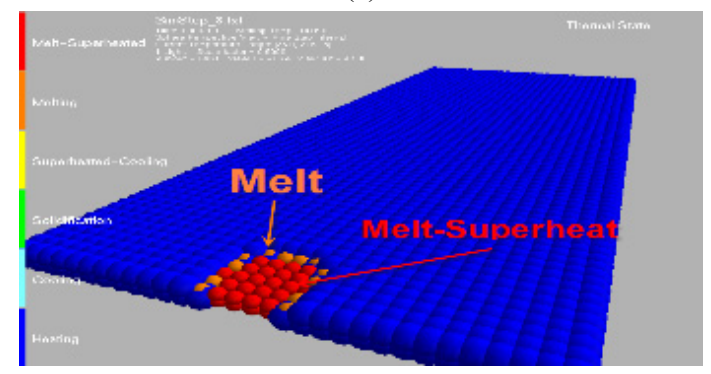

(c)

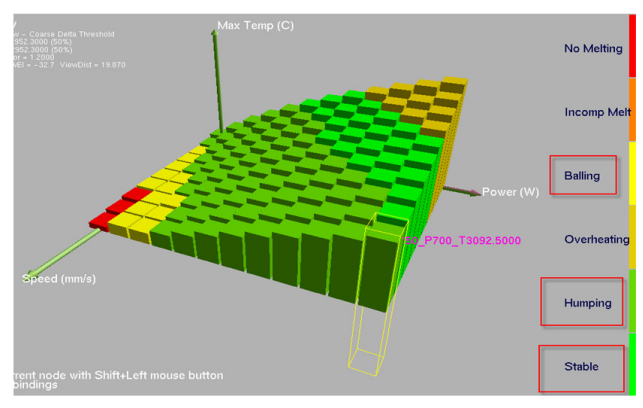

(b)

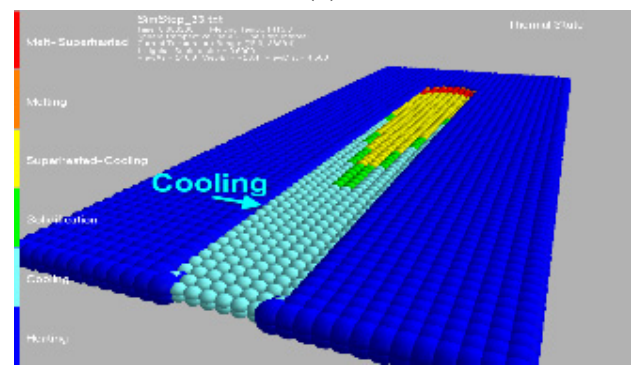

(d)

Figure 7. Laser powder bed fusion (LPBF) AM SS-316L Prediction/Validation different regions (humping, balling, stable): (a) Test: LPBF 2D Process Map (P-V); (b) Predicted ICME 3D Process $\operatorname{Map}(P, V, T) ;(\mathbf{c})$ Thermal State: Melt and melt-superheated regions; (d) Thermal State: Cooling and Solidification Regions. 


\subsubsection{Scatter and Uncertainty Evaluation and Allowable Generation}

Methods for Generic basis and Reduced Test Plan have been discussed in [17] about the need to qualify AM materials by computing A and B basis allowables similar to MMPDS [2] document. The number of required specimens for both A- and B-basis allowable determination is one hundred specimens. A total of 100 specimens from 10 heats and 10 lots. However, if test results do not fit any distribution, like Normal or Weibull, then an end-user would require 299 specimens from 10 heats and 10 lots. I have not seen any cases that the data does not fit any distractions. Therefore, in most cases, we will need 100 specimens. Please note this is required for tensile tests in order to develop yield and ultimate tensile strengths. If you have Tensile Allowables, then you need only 20 specimens for properties such as shear and compression Allowables. Reduced B-basis sampling would require the use of 20 samples, 3 heats and reduced lots. This will achieve certification/qualification virtually by computing an acceptance region across different batches/machines/process and utilizing the statistical acceptance values in qualification simulations (static, PSD) to virtually qualify the component [17]. There are three methods to qualify AM materials and parts: extensive testing, equivalence based/reduced testing for new process, and model-based (simulation) where testing is minimal [18]. We will attempt to use the model-based method. The first step would be to determine the generic basis acceptance region of the material across different batches/machines/process [6]. After that, we would utilize this acceptance region in qualification, proto-qualification, acceptance, prelaunch, and post launch validation requirements [3,18].

The Probabilistic Engine [17] is equipped with many methods including low- and high-fidelity methods such as first-order and second-order reliability methods (FORM and SORM), Advanced Mean Value, Adaptive Importance Sampling, and MCS (Monte Carlo Simulation).

Risk reduction is achieved by lowering the probability of failure of critical structures through the use of A- and B-basis design values. For A-basis, at least $99 \%$ of the population of material strength values is expected to equal or exceed this tolerance bound with $95 \%$ confidence. B-basis values are applied to redundant structures where failure would result in safe load redistribution. For B-basis, $90 \%$ of the population of material strength values is expected to equal or exceed that strength value. The approach for determination of strength allowable (Figure 6) with reduced testing builds on existing accepted standards and practices [17].

It uses statistics from Material level testing to reverse engineer microstructure uncertainties in void (shape, size, distribution) and material strength, and stiffness properties and manufacturing variables. These uncertainties are subsequently used in generating random virtual test samples for laminated notched and un-notched specimens. The virtual samples are then used in lieu of actual test samples.

The methodology combines probabilistic methods with advanced multi-scale, multi-physics progressive failure analysis (MS-PFA) [8,9] and Bayesian statistics to reduce the number of tests needed for determination of A- and B-basis strength values.

\section{Results and Discussion}

\subsection{Material Modeling—Strength Characterization, Qualification, Experimental Procedure}

Two Material systems are considered for strength allowable and fracture properties predictions: (1) LBFP Process, AlSi10Mg Coin Specimen; and (2) EBM Ti-64Al-4V Tensile specimen.

\subsubsection{AlSi10Mg Coin Specimen and LBFP Process}

Meltpool Engineering-Thermal Prediction Validation-of Void and Effect on AlSi10Mg Mechanical Properties 
Figure 8 shows Thermal transport prediction of Aluminum (AlSi10Mg) Transient Thermal-State for LPBF laser melting (Laser spot $80 \mathrm{~mm}, P=407 \mathrm{~W}$ and $V=1190 \mathrm{~mm} / \mathrm{s}$ ). This includes six process regions (heating, melting, melt-superheated, superheated-cooling, solidification/sintering and cooling). Figure $8 \mathrm{~b}$ shows the transient thermal states for a small laser spot at different time steps. Figure 8c shows the transient void ratios.

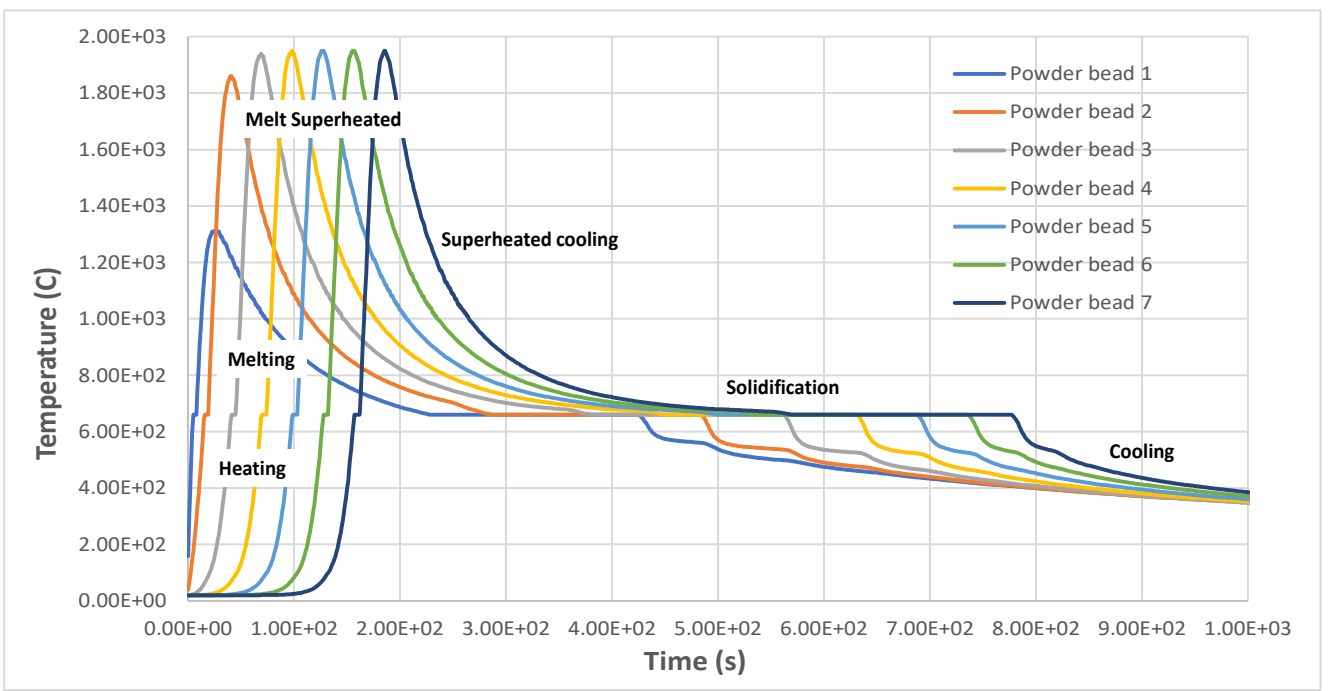

(a)

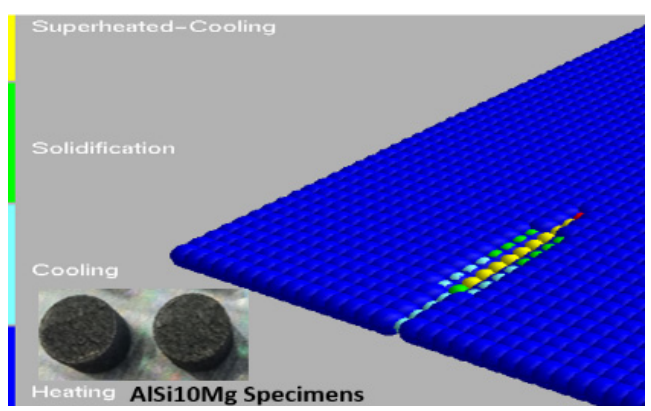

(b)

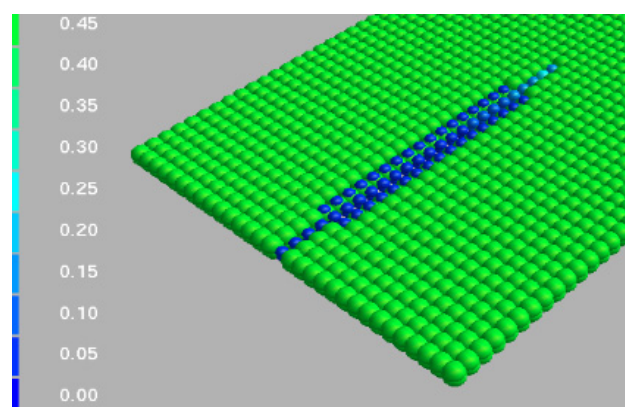

(c)

Figure 8. Thermal Transport Prediction of AlSi10Mg for LPBF laser melting (Laser spot $80 \mathrm{~mm}$, $P=407 \mathrm{~W}$ and $V=1190 \mathrm{~mm} / \mathrm{s}$ ): (a) Thermal history for the transient thermal state of several powder beads; (b) Transient melting states; (c) Transient void ratios.

\subsubsection{Experimental and Simulation Results for Porosity in AlSi10Mg}

The effect of different values of laser power and speed on density of AlSi10Mg specimens and their porosity has been evaluated in [7]. Microscale porosity was simulated, and experimental data and numerical results are compared in Figure 9 for different values of laser power and speed. 


\begin{tabular}{|c|c|c|c|c|c|}
\hline \multirow[b]{2}{*}{ Power (W) } & \multicolumn{5}{|c|}{ Laser Mark Speed $(\mathrm{mm} / \mathrm{s})$} \\
\hline & 1190 & 1295 & 1400 & 1470 & 1540 \\
\hline $\begin{array}{c}407 \\
\text { Experiment }\end{array}$ & $98.58 \%$ & $98.69 \%$ & $98.62 \%$ & $98.47 \%$ & $98.77 \%$ \\
\hline $\begin{array}{c}407 \\
\text { Simulation } \\
\end{array}$ & $98.82 \%$ & $98.79 \%$ & $98.84 \%$ & $98.88 \%$ & $98.91 \%$ \\
\hline Error & $0.2 \%$ & $0.1 \%$ & $0.2 \%$ & $0.4 \%$ & $0.1 \%$ \\
\hline $\begin{array}{l}388.5 \\
\text { Experiment }\end{array}$ & $98.99 \%$ & $98.96 \%$ & $98.88 \%$ & $98.77 \%$ & $98.56 \%$ \\
\hline $\begin{array}{c}388.5 \\
\text { Simulation } \\
\end{array}$ & $98.76 \%$ & $98.82 \%$ & $98.87 \%$ & $98.90 \%$ & $98.94 \%$ \\
\hline Error & $0.2 \%$ & $0.1 \%$ & $0.01 \%$ & $0.1 \%$ & $0.4 \%$ \\
\hline $\begin{array}{c}370 \\
\text { Experiment } \\
\end{array}$ & $99.10 \%$ & $99.10 \%$ & $98.96 \%$ & $98.99 \%$ & $98.77 \%$ \\
\hline $\begin{array}{c}370 \\
\text { Simulation } \\
\end{array}$ & $98.78 \%$ & $98.85 \%$ & $98.90 \%$ & $98.94 \%$ & $98.97 \%$ \\
\hline Error & $0.3 \%$ & $0.2 \%$ & $0.06 \%$ & $0.05 \%$ & $0.02 \%$ \\
\hline $\begin{array}{l}342.25 \\
\text { Experiment }\end{array}$ & $98.96 \%$ & $99.03 \%$ & $99.07 \%$ & $99.03 \%$ & $99.10 \%$ \\
\hline $\begin{array}{c}342.25 \\
\text { Simulation }\end{array}$ & $98.83 \%$ & $98.89 \%$ & $98.95 \%$ & $98.98 \%$ & $99.02 \%$ \\
\hline Error & $0.07 \%$ & $0.15 \%$ & $0.12 \%$ & $0.05 \%$ & $0.08 \%$ \\
\hline $\begin{array}{c}314.5 \\
\text { Experiment }\end{array}$ & $98.43 \%$ & $98.77 \%$ & $98.92 \%$ & $99.03 \%$ & $98.96 \%$ \\
\hline $\begin{array}{c}314.5 \\
\text { Simulation } \\
\end{array}$ & $98.89 \%$ & $98.95 \%$ & $99.01 \%$ & $99.04 \%$ & $99.07 \%$ \\
\hline Error & $.4 \%$ & $0.2 \%$ & $0.09 \%$ & $0.01 \%$ & $.1 \%$ \\
\hline
\end{tabular}

(a)

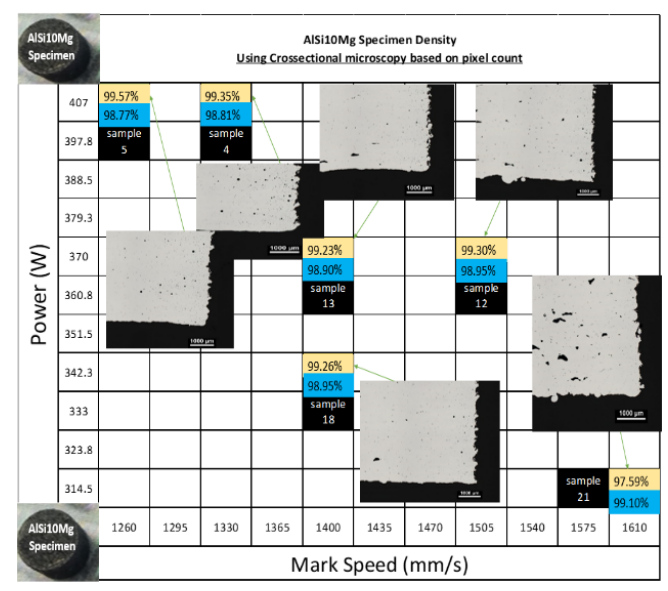

(b)

Figure 9. Comparison of experimental and simulation results for density of AlSi10Mg specimens: (a) Power vs. Speed; (b) Specimen Density Using Cross sectional microscopy based on pixel Count.

\subsubsection{Tensile Data Related to Build Orientation.}

Effect of Porosity and Print Orientation on Material Properties of AlSi10Mg is discussed (Table 3). It has been noted [11] that elastic modulus changes from $7.5 \times 10^{4} \mathrm{~N} / \mathrm{mm}^{2}$ for cast AlSi10Mg to $7.29 \times 10^{4} \mathrm{~N} / \mathrm{mm}^{2}$ for AM AlSi10Mg with AM voids. Tensile and compressive strength changes from $2.10 \times 10^{2} \mathrm{~N} / \mathrm{mm}^{2}$ for cast AlSi10Mg to $1.7957 \times 10^{2} \mathrm{~N} / \mathrm{mm}^{2}$ for AM AlSi10Mg with AM voids. Poisson's ratio changes from 0.3 for cast AlSi10Mg to 0.297 for AM AlSi10Mg with AM voids. Density changes from $2670 \mathrm{~kg} / \mathrm{m}^{3}$ for cast AlSi10Mg to $2605 \mathrm{~kg} / \mathrm{m}^{3}$ for AM AlSi10Mg with AM voids.

Table 3. Experimental Data-Scatter in Material Parameters of AlSi10Mg [11].

\begin{tabular}{|c|c|c|c|}
\hline Parameters & Value & Range & Build \\
\hline Max Strength & $4.22 \mathrm{KN}$ & $0.2 \mathrm{kN}$ & $a_{x}=0^{\circ}$ \\
\hline Ultimate Displacement & $210 \mathrm{~mm}$ & $30 \mathrm{~mm}$ & $\alpha_{x y}=5^{\circ}$ \\
\hline Max Strength & $3.72 \mathrm{kN}$ & $0.5 \mathrm{kN}$ & $\alpha_{x}=0^{*}$ \\
\hline Ultimate Displacement & $145 \mathrm{~mm}$ & $55 \mathrm{~mm}$ & $\alpha_{x y}=5^{\circ}$ \\
\hline Max Strength & $3.7 \mathrm{kN}$ & $0.2 \mathrm{kN}$ & \multirow{2}{*}{$\begin{array}{l}\alpha_{\alpha_{x}}=90^{\circ} \\
\alpha_{\mathrm{xy}}=45^{\circ}\end{array}$} \\
\hline Ultimate Displacement & $235 \mathrm{~mm}$ & $65 \mathrm{~mm}$ & \\
\hline
\end{tabular}

The Structural Requirements are Tensile Properties: (i) Minimum Tensile Strength: $130 \mathrm{ksi}$; (ii) Minimum Elongation: 5\%; and (iii) Minimum Yield Strength: 119 ksi. Table 3 shows the Tensile Data Related to Build Orientation: (a) oxygen content, and (b) scatter in mechanical properties (UTS, $\mathrm{YS}, \mathrm{El} \%$, and RA). Figure 10 shows the predicted stress-strain curve in $\mathrm{XY}, \mathrm{YZ}$, and $\mathrm{XZ}$ directions vs. test observations. 


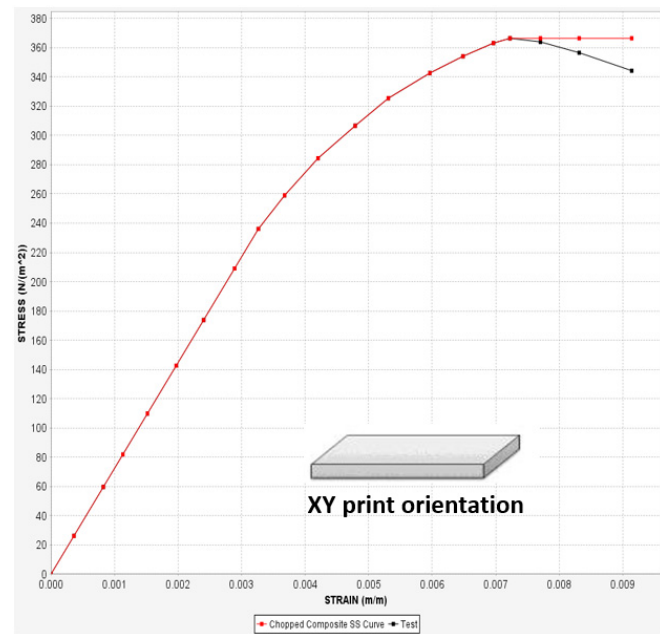

(a)

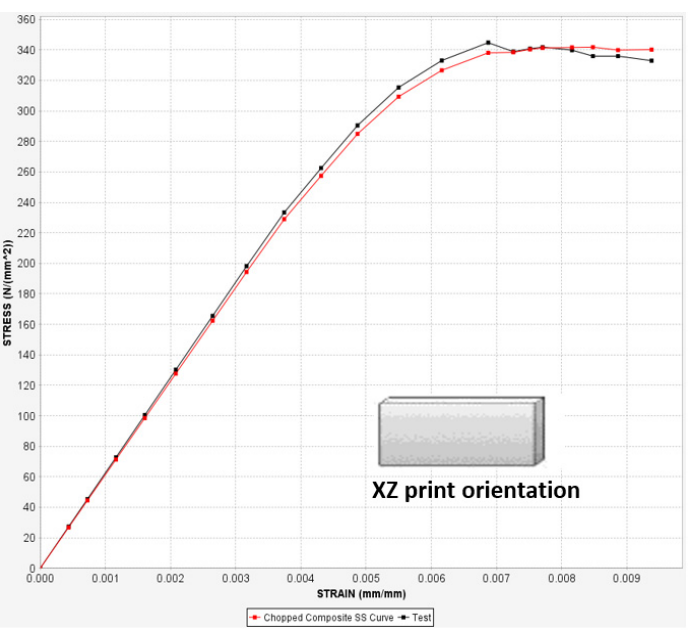

(b)

Figure 10. Stress-strain curves of dog bone specimens printed with $X Y$ and $X Z$ orientation with ellipsoidal voids $(0.13 \mathrm{~mm} \times 0.06 \mathrm{~mm} \times 0.06 \mathrm{~mm})$ : predicted (red) by MCQ and test (black). (a) void ratio of $0.0, \mathrm{XY}$ orientation; (b) void ratio of $0.01, \mathrm{XZ}$ orientation.

3.1.4. A-B Basis AlSi10Mg Strength Allowable and Sensitivity Analysis to Variations of Material Properties

Figure 11 shows Variations of Test Values of Strength of AlSi10Mg. Figure 12a shows Allowable $(A-B)$ basis value prediction-compared with test. $A$-Basis is defined as a strength value at which only 1 in 100 specimens will fail with a 95\% confidence level. B-Basis is a strength value at which only 10 in 100 specimens will fail with a $95 \%$ confidence level. The following formula is used to determine a $A$ - and $B$-basis value for normal distribution: $B=\bar{X}-k_{\mathrm{B}}(s)$, where $\mathrm{X}$ is the arithmetical Mean, $\mathrm{k}$ is a constant (called the tolerance factor) depending on the number of specimens, $n$, and $s$ is the standard deviation. Figure $12 \mathrm{~b}$ shows the Sensitivity Analysis of Strength of AlSi10Mg to Variations of Material Properties, indicating that increasing the void and reducing material shear strength have positive and negative sensitivity, respectively. Positive sensitivity to void ratio means that increasing the void ratio has a negative effect on strength. Negative sensitivity to shear strengths means that increasing these material properties results in higher strength.

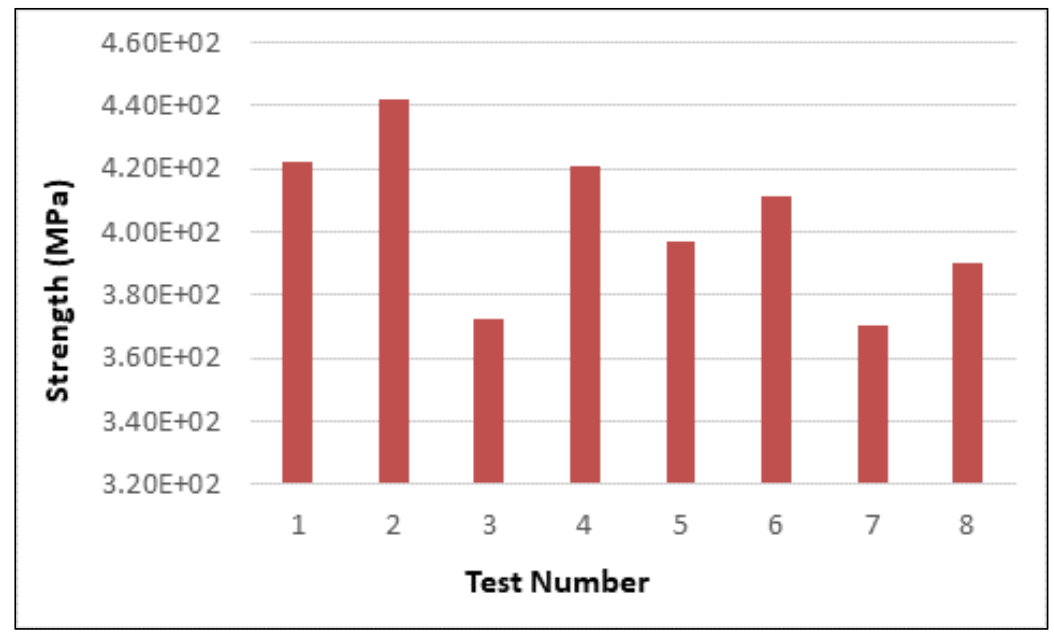

Figure 11. Variations of Test Values of Strength of AlSi10Mg. 


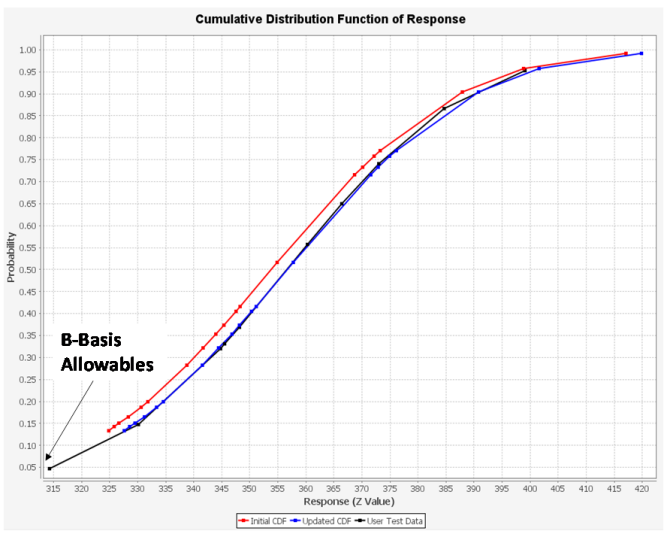

(a)

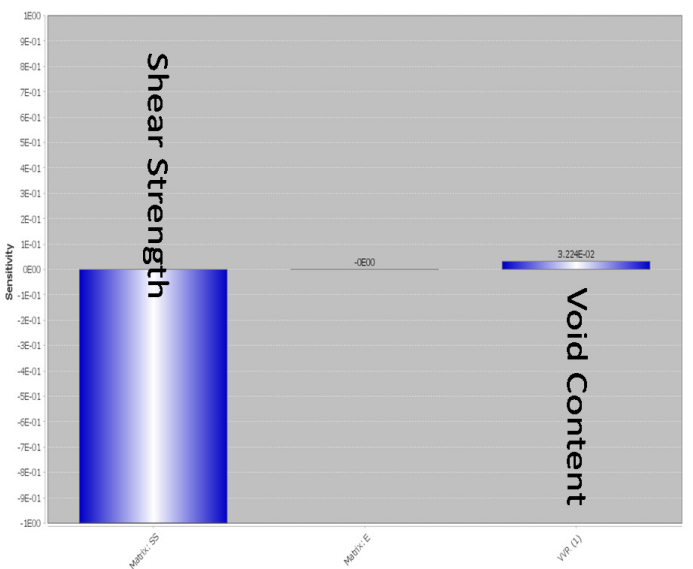

(b)

Figure 12. AlSi10Mg $A-B$ Allowables: (a) CDF plot of Strength; (b) Sensitivity analysis of strength.

\subsubsection{Fracture Toughness Determination and Fatigue Crack Growth for AlSi10Mg}

Table 4 shows Fracture toughness of AlSi10Mg [18] for three different print orientations. Figure 13 Shows the Fracture toughness of AlSi10Mg printed in XY, XZ and YZ print orientation in the table. The generated stress-strain curve for each orientation due to void is used as input to FTD.

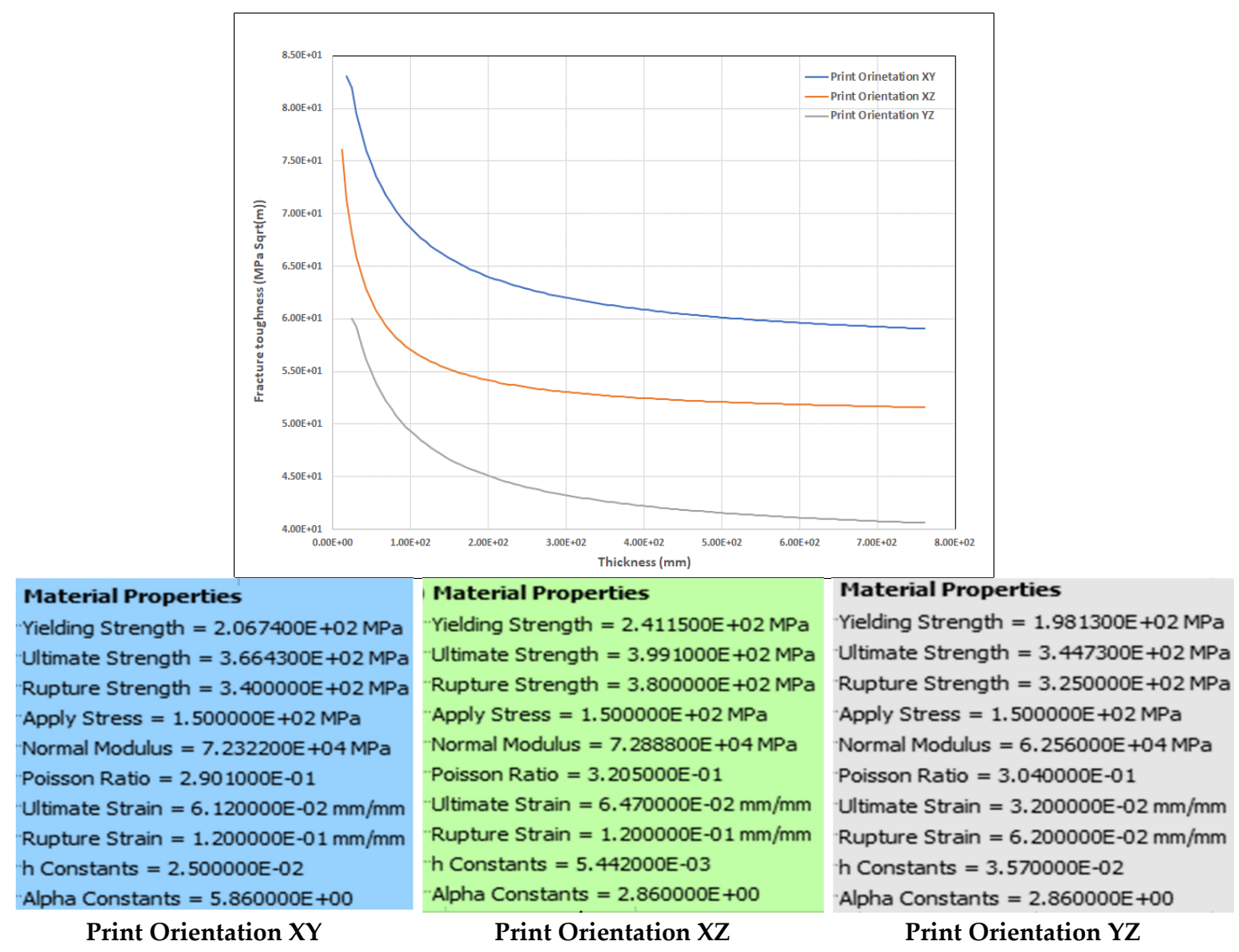

Figure 13. Fracture toughness of AlSi10Mg printed in the $\mathrm{XY}, \mathrm{XZ}$ and $\mathrm{YZ}$ print orientations. 
Table 4. Fracture toughness of AlSi10Mg [18].

\begin{tabular}{|c|c|c|c|c|}
\hline Orinetation & $\begin{array}{c}K_{\mathrm{IC}} \\
(\mathrm{MPa} \sqrt{m})\end{array}$ & $\begin{array}{c}\text { Standard Deviation } \\
(\mathrm{MPa} \sqrt{m})\end{array}$ & $\begin{array}{l}\text { Genoa Predictions } \\
(\mathrm{MPa} \sqrt{m})\end{array}$ & Print Orientation \\
\hline$X Y$ & 59.06 & 1.43 & 59.06 & \\
\hline$X Z$ & 51.6 & 1.79 & 51.6 & \\
\hline$Y Z$ & 40.63 & 1.25 & 40.63 & \\
\hline
\end{tabular}

\subsection{Allowable Generation of Ti64Al4V and EBM Process}

\subsubsection{Print Orientation Effect on Tensile Strength and Strain}

The effects of heat treatment on the investigated SLM parts are attributed to the formation of precipitates in the material matrix, as well as the altering of other micro structural features, i.e., phase volume fraction, grain size and morphology, while the build orientation has direct influence on the damage evolution under loading. A part's building orientation during SLM influences its cooling rate (due to the part's aspect ratio), and thus encumbered microstructure, while the final orientation of deposited layers (which depend on build direction) impacts part strength in various loading directions.

\subsubsection{Scatter of Titanium Properties at Room (RT) and High Temperature (HT)}

Table 5 shows typical RT Tensile Properties for EBM Ti-6Al-4V. The probabilistic sensitivities in this section will show that in order for the next-generation technology to improve the strength of 3D printed materials, they must control the porosity volume fraction and orientation of voids. This 3D EBM material is shown to be over $99.99 \%$ reliable. Scatter of 3D printed Ti-6Al-4V mechanical properties (Yield, Ultimate, Elongation, and Reduction of Area) have been observed at room and high temperature (RT/HT). The MCQ Code prediction capabilities are used to show variation in Stress-Strain Curves Characteristic Points and Residual Stress due to porosity (void/defect) shape and size and orientation similar to those found after the EBM 3D printed Ti-6Al-4V process. Figure 14 also shows the variation of strength with respect to manufacturing process parameters at RT and $\mathrm{HT}\left(700^{\circ} \mathrm{C}\right)$. The samples were fabricated horizontally and vertically in multiple directions to find the effect on the mechanical properties such as UTS, YS, and \%EL. The vertical and horizontal rod specimens are 2 inches in length and 0.25 in diameter (Table 6).

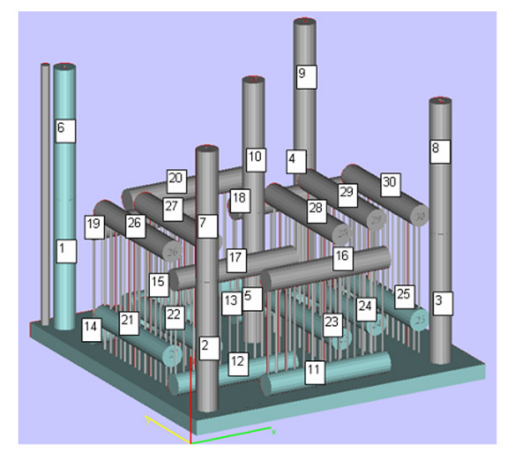

(a)

\begin{tabular}{|c|c|c|c|c|}
\hline RT & UTS, Ksi & YS, ksi & El, \% & RA, \% \\
\hline Mean & 146.1 & 141.1 & 13.9 & 30.1 \\
\hline SD & 2.8 & 4.0 & 1.2 & 7.4 \\
\hline COV & 1.9 & 2.8 & 8.8 & 24.7 \\
\hline HT & UTS, Ksi & YS, ksi & El, \% & RA, \% \\
\hline Mean & 96 & 78.05 & 19.1 & 55.55 \\
\hline SD & 2.3 & 2.7 & 0.8 & 5.6 \\
\hline COV & 2.4 & 3.4 & 4.2 & 10.0 \\
\hline \multicolumn{5}{|r}{}
\end{tabular}

(b)

Figure 14. 3D Printed Ti-4Al-4V Tensile Tests by EBM Process: (a) Horizontal and Vertical Pint; (b) Strength Scatter at RT/HT. 
Table 5. Typical RT Tensile Properties for EBM Ti-6Al-4V.

\begin{tabular}{ccccc}
\hline Ti-6Al-4V & Cast & $\begin{array}{c}\text { Wrought } \\
\text { (Annealed) }\end{array}$ & $\begin{array}{c}\text { EBM-As } \\
\text { Deposited }\end{array}$ & EBM-HIP'd \\
\hline UTS, ksi (MPa) & $145(1000)$ & $135(930)$ & $150(1037)$ & $139(957)$ \\
YS, ksi (MPa) & $130(896)$ & $128(895)$ & $137(948)$ & $131(905)$ \\
EI, \% & 8 & 12 & 15 & 17 \\
RA, \% & - & - & 44 & 57 \\
\hline
\end{tabular}

Table 6. Tensile Data Related to Build Orientation.

\begin{tabular}{|c|c|c|c|c|c|c|c|}
\hline MOR \# & Oxygen \% & $\begin{array}{l}\text { Density, } \\
\text { g/cc }\end{array}$ & $S / N$ & UTS, ksi & YS, ksi & EI, \% & RA, \% \\
\hline \multirow{2}{*}{221} & \multirow{2}{*}{0.19} & \multirow{2}{*}{4.3818} & ZCoupon & 139 & 131 & 16 & 19 \\
\hline & & & X-Y Coupon & 136 & 128 & 16 & 35 \\
\hline \multirow{2}{*}{222} & \multirow{2}{*}{0.19} & \multirow{2}{*}{4.3837} & Z Coupon & 141 & 133 & 21 & 46 \\
\hline & & & X-Y Coupon & 134 & 126 & 19 & 36 \\
\hline \multirow{2}{*}{233} & \multirow{2}{*}{0.14} & \multirow{2}{*}{4.3918} & Coupon & 139 & 132 & 20 & 43 \\
\hline & & & X-Y Coupon & 139 & 131 & 20 & 49 \\
\hline \multirow{2}{*}{234} & \multirow{2}{*}{0.15} & \multirow{2}{*}{4.3728} & Z Coupon & 143 & 132 & 18 & 50 \\
\hline & & & X-Y Coupon & 139 & 131 & 11 & 16 \\
\hline \multirow{2}{*}{242} & \multirow{2}{*}{0.20} & \multirow{2}{*}{4.3674} & Z Coupon & 144 & 134 & 16 & 38 \\
\hline & & & X-Y Coupon & 142 & 131 & 16 & 34 \\
\hline \multirow{2}{*}{249} & \multirow{2}{*}{0.13} & \multirow{2}{*}{4.4087} & Z Coupon & 148 & 138 & 16 & 38 \\
\hline & & & X-Y Coupon & 143 & 133 & 15 & 37 \\
\hline Requiment & $\operatorname{Max} 0.2 \%$ & None & - & Min 130 & Min 119 & Min 5 & None \\
\hline
\end{tabular}

\subsubsection{Material Modeling and the Integrated Computational Material Engineering (ICME)}

MCQ software and methods was used to predict A/B basis allowables including the material mechanical properties (stiffness, strength) at different temperatures, and probabilistic Sensitivity Analysis with respect to Process defects.

MCQ predictions were validated with Ti-6Al-4V to be able to predict static and fatigue DMLS printed metal properties and allowables at room and high temperature. The static properties were predicted by mixing Ti6Al4V base metal properties stress-strain curve prediction considering defects (void) percentages and compared to test (Figure 15) of 3D printed Direct Metal Laser Sintered (DMLS) material using nano-based inclusion/defects algorithm: A nano-mechanics-based material modeling tool was used to predict stress-strain curves with effect of air particles as voids. The defect volume percentage, shape (ellipsoid shown), and aspect ratios are used as inputs to predict stiffness and strength in all directions. Output properties can be isotropic, orthotropic, or anisotropic. The Wrought with Air Particles is the simulation curve and the Laser Engineered Net Shaping (LENS) is the tested printed material. The SS curve was idealized in black in the top right of Figure 15 to be able to predict fracture toughness vs thickness. The plane strain fracture toughness is then fed into computations for fatigue crack growth determinations and the results of the MCQ metals prediction (FCG) are compared with test Ti6Al4V DMLS Milled. Furthermore, the da/dN vs. dG curve is used as input to an FE model to determine the fatigue (S-N) life of the part. A separate parameter accounted for additional observed surface roughness. The S-N prediction matched the DMLS As Built test data, which is a reduced life compared to milled specimens. The FTD and FCG process is the result of two theoretically based breakthrough methodologies for metals that compute fracture/crack growth properties from stress-strain curves, as shown in Figure 16. The capability has been accepted by ASTM [19]. 


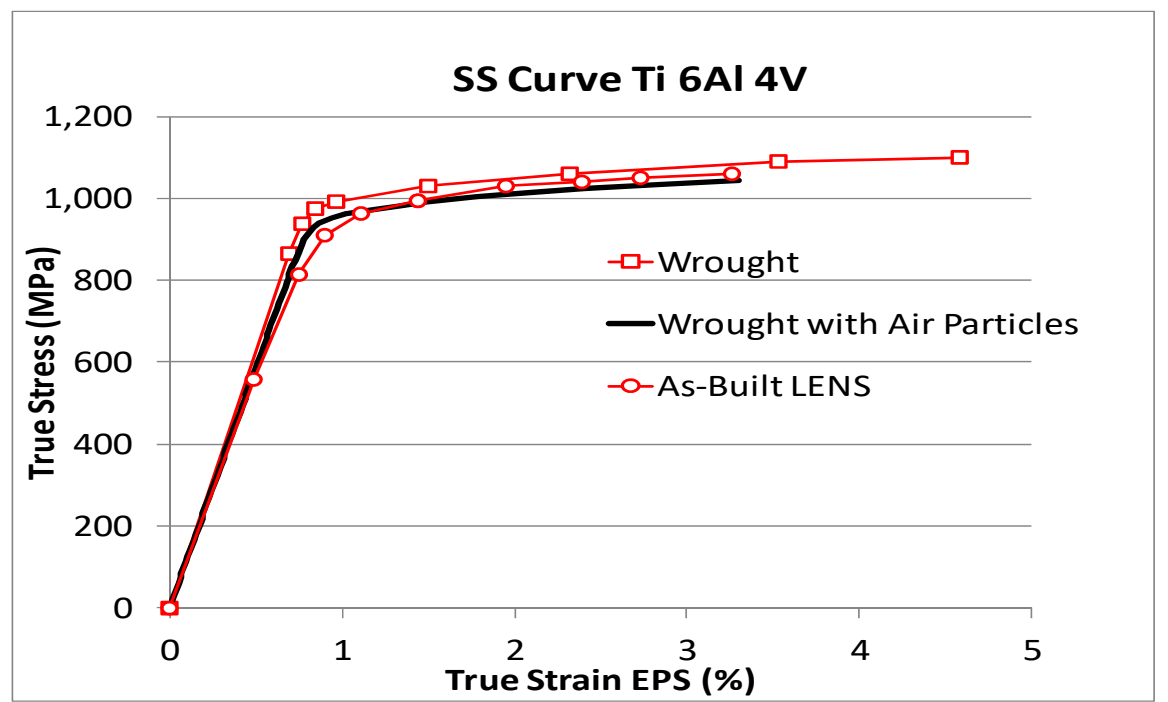

Figure 15. Predicted Stress-Strain Curve TI with Defects of 3D printed direct metal laser sintered (DMLS) material.

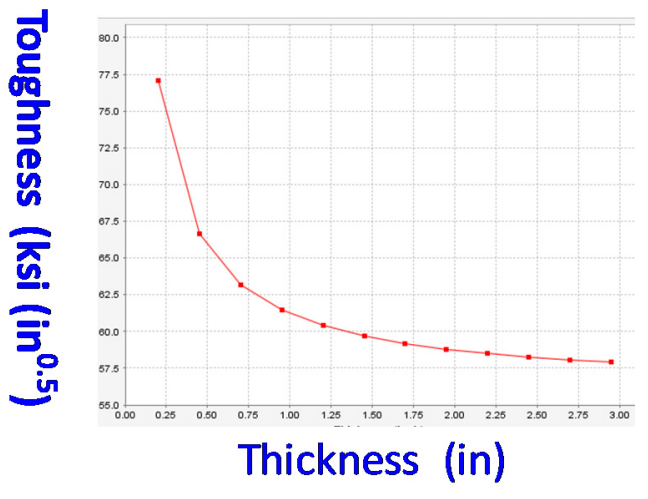

(a)

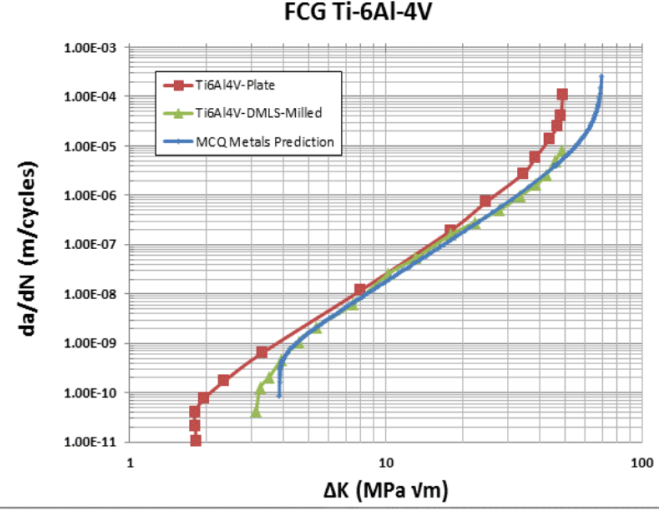

(b)

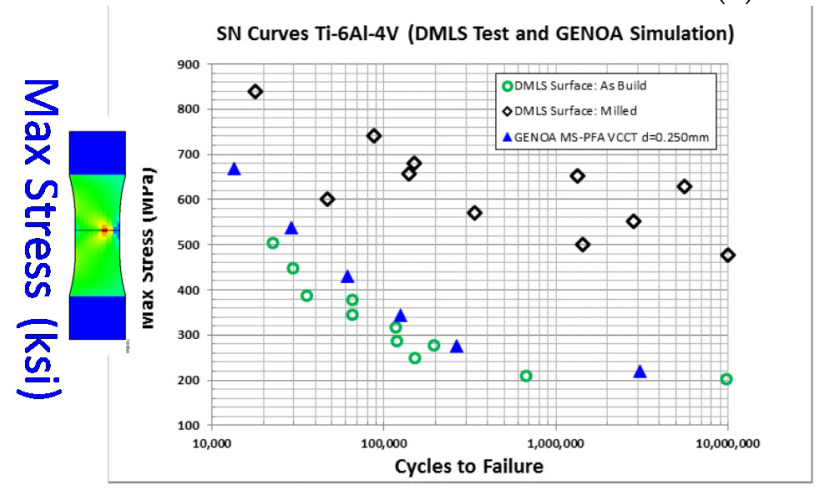

Fatigue Life N (Cycles)

(c)

Figure 16. AM Validation: Fracture, Fatigue Properties of Un-Notched/Notched Specimen of Ti6Al4V, DMLS at RT: (a) Toughness vs. Thickness; (b) Fatigue Crack Growth vs. Test, W/o Printing; (c) S-N Prediction/Validation $R=0.1$. 


\subsubsection{Material Modeling-Source of Scatter and Uncertainties for EBM Process}

The input Properties for Ti6Al4V and Inclusions (Table 7a-c) and baseline Stress-Strain (Figure 17) show that we utilize the Wrought properties of Ti-6Al-4V, add inclusions, their shape (cylindrical, ellipsoidal, etc.), size ratios (length, width and height), and volume fraction to predict strength.

Table 7. Input Properties for Ti6Al4V and Inclusions.

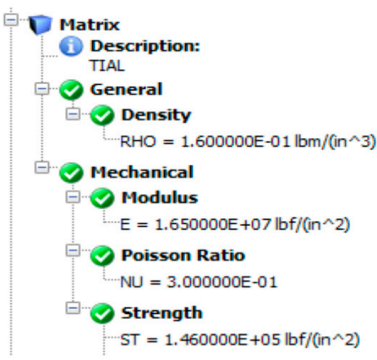

(a) Ti6Al4V (Wrought)

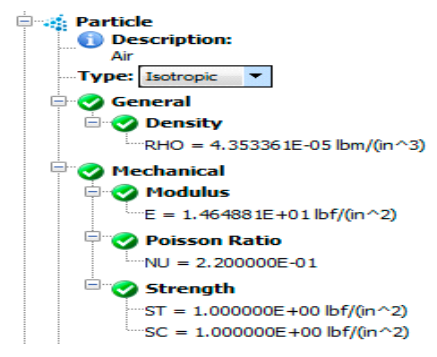

(b) Inclusion Air

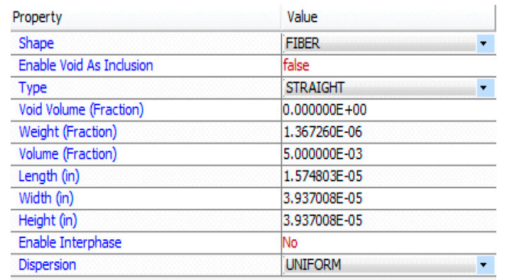

(c) Inclusion Air

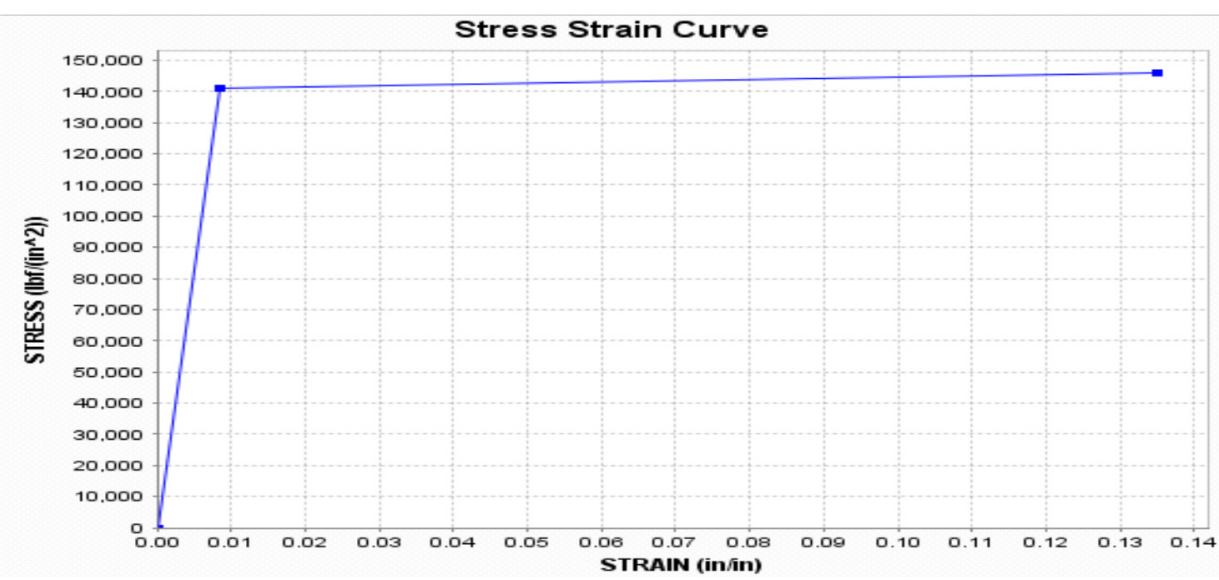

Figure 17. Baseline Stress-Strain Curve for Ti6Al4V.

Test observation showed that print direction will affect stiffness, and strength. Void shape and size are key in determining properties. Scatter Coefficient of Variation (COV) prediction was performed with acceptable results at room and high temperature. After random variations of the inputs (Table 7), a response surface is formed and used in a probabilistic simulation (Figure 18), which computes a CDF (Figure 18a) and probabilistic sensitivities (Figure 18b) for Yield Strength, Ultimate Strength, and \%Elongation. Figure 19 shows SS Curve variations (Figure 19a) and zoomed in to show several yield strengths (Figure 19b) and UTS and Elongations (Figure 19c). The percentage differences for RT and HT allowables predictions are under 10\% for mean and standard deviation predictions (Table 8). With knowledge of the CDF and design requirements in Table 9 (Min YS119 ksi, Min UTS130 ksi, and Min 5\% Elongation), we can say that this 3D printed material is over 99.99\% reliable for all requirements. 

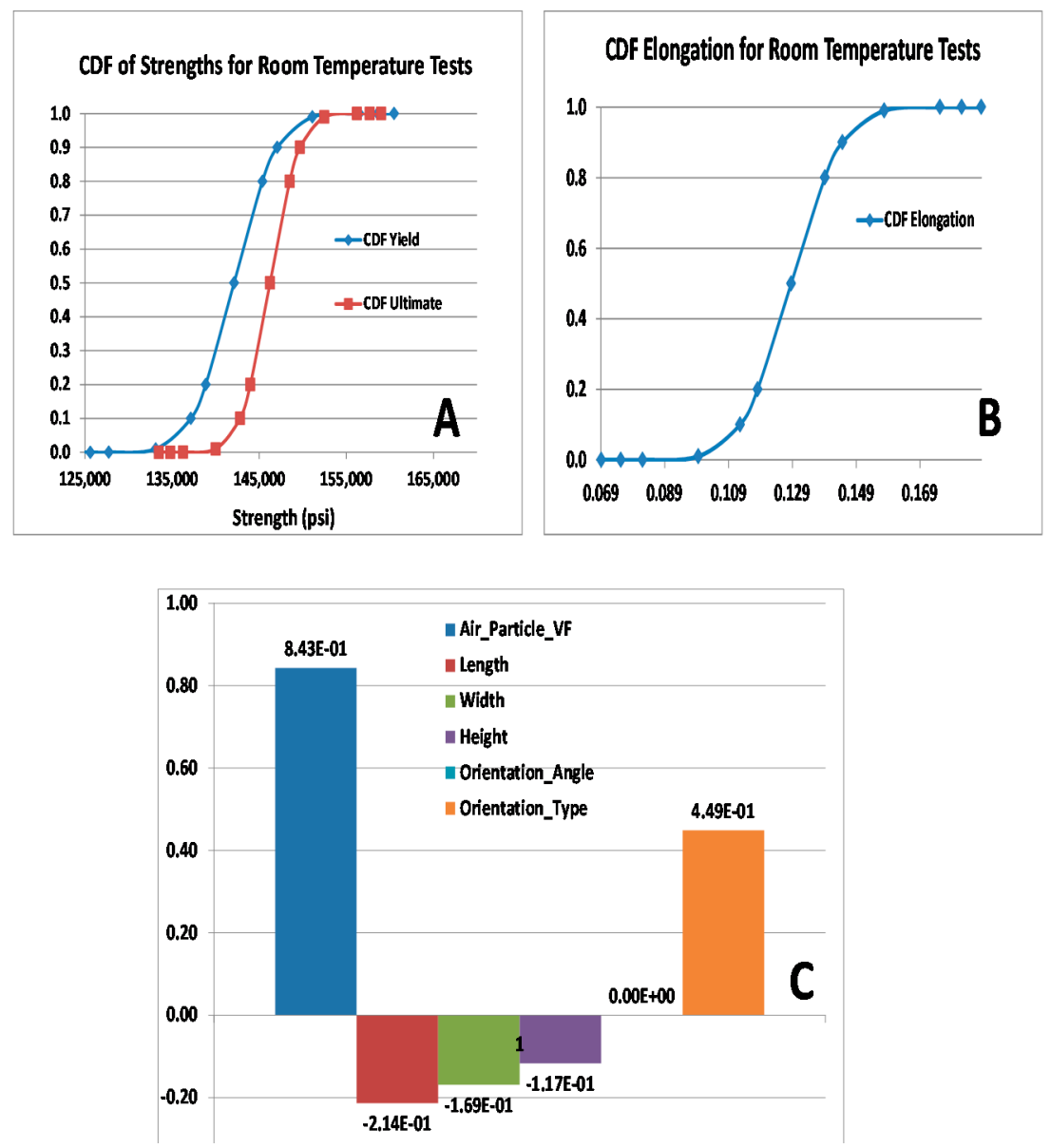

Figure 18. Predicted Strength Allowable and sensitivity of Ti-64Al-4V: CDF of Ultimate, yield (A), and elongation (B); (C) Sensitivity to strength: Dominant factors (Void Content, and Orientation).

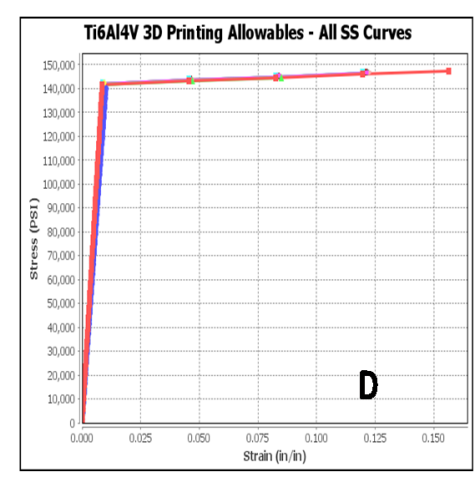

(a)

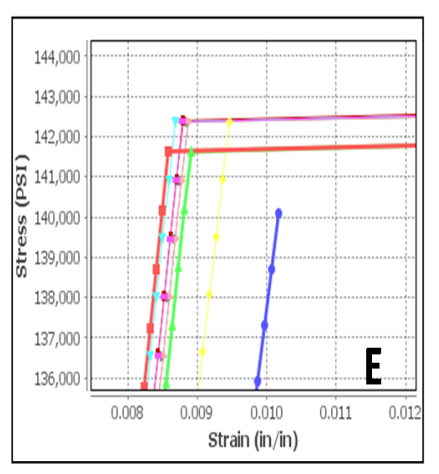

(b)

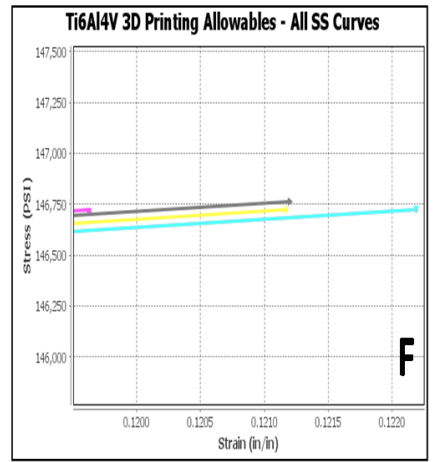

(c)

Figure 19. Ti-6Al-4V SS Curve variations: zoomed in to several yield strengths UTS and Elongations: (a) SS Curve Predicted by MCQ; (b) Yield Strength Variation; (c) UTS: \%Elongation Variation. 
Table 8. Random variables (cause of scatter).

\begin{tabular}{ccccc}
\hline RV Name & Mean Value & $\begin{array}{c}\text { Standard } \\
\text { Deviation }\end{array}$ & $\begin{array}{c}\text { Distribution } \\
\text { Type }\end{array}$ & COV \\
\hline Air Particle VF & $5.00 \times 10^{-3}$ & $2.50 \times 10^{-4}$ & Normal & 0.05 \\
Length & $1.57 \times 10^{-5}$ & $7.85 \times 10^{-7}$ & Normal & 0.05 \\
Width & $3.94 \times 10^{-5}$ & $1.97 \times 10^{-6}$ & Normal & 0.05 \\
Height & $3.94 \times 10^{-5}$ & $1.97 \times 10^{-6}$ & Normal & 0.05 \\
Orientation Angle & 0 & 0 & Normal & 0.05 \\
Orientation Type & 3.00 & $1.50 \times 10^{-1}$ & Normal & 0.05 \\
\hline
\end{tabular}

Table 9. EBM 3D Printed RT/HT Test allowables vs. MCQ Prediction.

\begin{tabular}{ccc|c|cc|c|cc|c}
\hline RT & YS, Ksi & MCQ & \%Diff & UTS, Ksi & MCQ & \%Diff & EI, \% & MCQ & \%Diff \\
\hline Mean & 141.1 & 142.1 & -0.7 & 146.1 & 146.2 & -0.1 & 13.9 & 12.6 & 9.4 \\
SD & 3.96 & 3.86 & 2.4 & 2.81 & 2.68 & 4.5 & 1.22 & 1.25 & -2.6 \\
COV (\%) & 2.81 & 2.72 & 3.1 & 1.92 & 1.83 & 4.6 & 8.78 & 9.76 & -11.1 \\
\hline HT & YS, Ksi & MCQ & \%Diff & UTS, Ksi & MCQ & \%Diff & EI, \% & MCQ & \%Diff \\
\hline Mean & 78.1 & 75.3 & 3.5 & 96.0 & 87.7 & 8.6 & 19.1 & 18.2 & 4.9 \\
SD & 2.83 & 2.79 & 1.4 & 2.46 & 2.55 & -3.8 & 0.84 & 0.91 & -7.4 \\
COV (\%) & 3.63 & 3.71 & -2.2 & 2.56 & 2.91 & -13.6 & 4.42 & 4.98 & -12.9 \\
\hline
\end{tabular}

\section{Conclusions}

AM Part qualification requires Mechanical Strength and scatter measurement, and establishment of fracture control plan. The ICME Material Characterization and Qualification (MCQ) software material model prediction capabilities are used to predict: (a) Material Allowables, Stress-Strain Curves, and Residual Stress. The probabilistic simulation computes (i) the probabilistic sensitivities for Yield Strength, Ultimate Strength, and \%Elongation as well as A and B basis allowables; (ii) the Fracture Control Plan for fracture toughness determination, and (iii) fatigue crack growth vs. stress intensity of the As-Built 3D printed material.

As part of case study effort, two AM modalities were chosen: (1) LPBF manufacturing of AlSi10Mg, and (2) EBM Manufacturing of Ti-6Al-4V demonstrated for Part Quality assurance. The latter component ensured that all physical and mechanical properties met or exceeded requirements. Scatter and Uncertainty in Material mechanical properties were predicted and compared with test data. A-B Basis allowables were generated based on reduced testing technique. As part of the fracture control plan, fracture and fatigue properties were computed and compared with test data, and found to be in a good agreement with the data.

Author Contributions: Conceptualization, F.A.; Writing Original Draft, F.A.; Formal Analysis, F.A., C.G., V.H., and P.Y.; Editing, F.A., C.G., V.H., and P.Y.; All authors have read and agreed to the published version of the manuscript.

Funding: This research funded by Various DoD SBIR projects.

Acknowledgments: One test validation has been conducted with the data produced by University of Dayton Research Institute (UDRI) for porosity of AlSi10Mg for a DoD SBIR project directed by AlphaSTAR Corporation.

Conflicts of Interest: The authors declare no conflict of interest.

\section{Nomenclature}

$\begin{array}{ll}\text { AM } & \text { Additive manufacturing } \\ \text { CDF } & \text { Cumulative Distribution Function } \\ \text { da/dn-K } & \text { crack growth rate/Cycle Vs. stress intensity } \\ \text { D\&DT } & \text { Durability and Damage Tolerance } \\ \text { DED } & \text { Direct Energy Deposition } \\ \text { DMLS } & \text { Direct metal laser sintering } \\ \text { DOE } & \text { Design of Experiment }\end{array}$




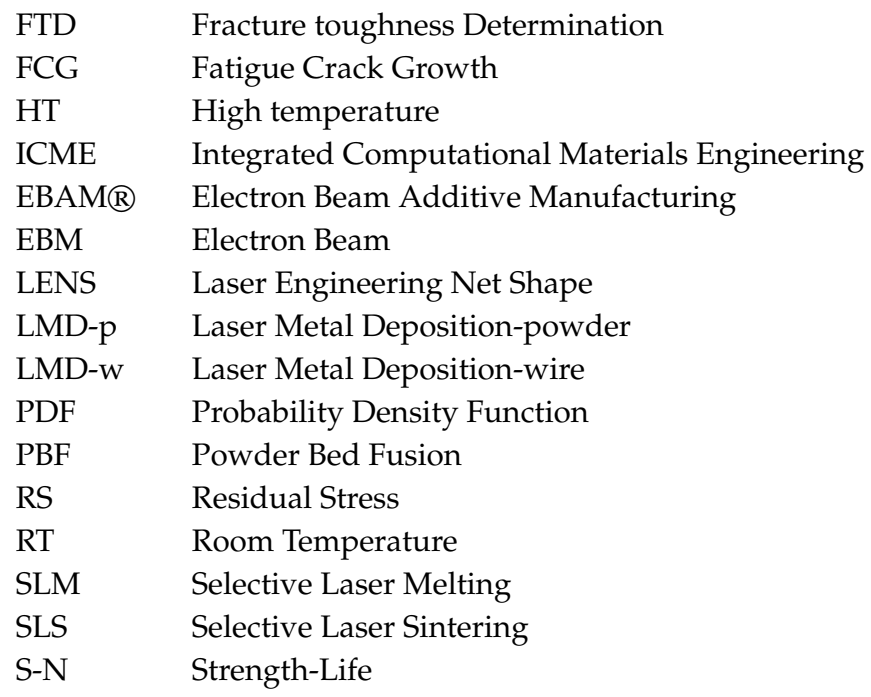

\section{References}

1. Audit of DoD's. Use of Additive Manufacturing for Sustainment Parts; Report No. DODIG-2020-003, Project No. D2019-D000AT-0057.000; Office of Inspector General, US Department of Defense: Washington, DC, USA, 2019.

2. Rice, R.C.; Goode, R.; Bakuckas, J.; Thompson, S. Development of MMPDS Handbook aircraft design allowables. In Proceedings of the 7th Joint DOD/FAA/NASA Conference on Aging Aircraft, New Orleans, LA, USA, 8-11 September 2003.

3. Air Force Space Command. SMC Standard SMC-S-016 Test Requirements for Launch, Upper-stage and Space Vehicles; Air Force Space Command: El Segundo, CA, USA, 2014.

4. Spears, T.G.; Gold, S.A. In-process sensing in selective laser melting (SLM) additive manufacturing. Integr. Mater. Manuf. Innov. 2016, 5, 16-40. [CrossRef]

5. ASTM International. ASTM Committee F42 Standard Terminology for Additive Manufacturing Technologies; ASTM International: West Conshohocken, PA, USA, 2012.

6. William, E.F. Metal additive manufacturing: A review. J. Mater. Eng. Perform. 2014, 23, 1917-1928. [CrossRef]

7. Mani, M.; Feng, S.; Lane, B.; Donmez, A.; Moylan, S.; Fesperman, R. Measurement Science Needs for Real-time Control of Additive Manufacturing Powder Bed Fusion Processes; U.S. Department of Commerce: Washington, DC, USA, 2015. [CrossRef]

8. Yadollahi, A.; Shamsaei, N.; Thompson, S.M.; Elwany, A.; Bian, L. Effects of building orientation and heat treatment on fatigue behavior of selective laser melted 17-4 PH stainless steel. Int. J. Fatigue 2017, 94, 218-235. [CrossRef]

9. Godines, C.; DorMohammdi, S.; Frank Abdi, D.; Huang, I.; Roche, R. 3D print -material and process model and effect of defects on part performance. In Proceedings of the Science in the Age of Experience Simulia User Conference, Boston, MA, USA, 18-21 June 2018.

10. Abdi, F.; Garg, M. Characterization of Nanocomposites Technology and Industrial Applications; CRC Press: Boca Raton, FL, USA, 2017; ISBN 978-1-315-36489-6.

11. ASTM International. STP 1450 Probabilistic Aspect of Life Prediction; ASTM International: West Conshohocken, PA, USA, 2004.

12. Nikbin, K.; Smith, D.J.; Webster, G. A prediction of creep crack growth from uniaxial creep data. Proc. R. Soc. A Math. Phys. Eng. Sci. 1984, 396, 183-197.

13. Saxena, A. Creep and creep-fatigue crack growth. Int. J. Fract. 2015, 191, 31-51. [CrossRef]

14. Abdi, F.; Miraj, R.; Tam, C.; Rios, I.R.; Harik, V. AM part qualification by icme analysis and real time NDE monitoring. Model Based Enterp. Summit (MBE 2020) 2020, 2020, 5-203.

15. Abdi, F.; Tam, C.; Anderson, S.; Moazami, N.; Nikbin, K.; Godines, C.; Tandon, G.; Harik, V.; Miraj, R. Sensory real-time in-situ monitoring toolset for additive manufactured parts. SAMPE J. 2019. Available online: https://app.robly.com/archive?id=0084c0f99444b04fc70dfa722c734f37\&v=true (accessed on 28 June 2020). 
16. Torries, B.; DorMohammadi, S.; Abdi, F.; Thompson, S.; Shamsaei, N. Topology optimization of an additively manufactured beam. In Proceedings of the Annual International Solid Freeform Fabrication Symposium (SFF Symp 2017), Austin, TX, USA, 7 August 2017.

17. Abdi, F.; Clarkson, E.; Godines, C.; DorMohammadi, S.; de Fenza, A. A-B Basis Allowable Test Reduction Approach and Composite Generic Basis Strength Values; AIAA SciTech: Reston, VA, USA, 2016.

18. Hitzler, L.; Hirsch, J.; Schanz, J.; Heine, B.; Merkel, M.; Hall, W.; Öchsner, A. Fracture toughness of selective laser melted AlSi10Mg. Proc. Inst. Mech. Eng. Part L J. Mater. Design Appl. 2019, 233, 615-621. [CrossRef]

19. Greitemeier, D.; Holzinger, V.; Dalle Donne, C.; Eufinger, J.; Melz, T. Fatigue prediction of additive manufactured Ti-6Al-4V for aerospace: Effect of defects, surface roughness. In Proceedings of the 28th ICAF Symposium, Helsinki, Finland, 3-5 June 2015.

(C) 2020 by the authors. Licensee MDPI, Basel, Switzerland. This article is an open access article distributed under the terms and conditions of the Creative Commons Attribution (CC BY) license (http://creativecommons.org/licenses/by/4.0/). 